\title{
A review on molten-salt-based and ionic-liquid-based nanofluids for medium-to-high temperature heat transfer
}

\author{
Wei Wang ${ }^{1,2} \cdot$ Zan $\mathrm{Wu}^{2} \cdot$ Bingxi $\mathrm{Li}^{1} \cdot$ Bengt Sundén ${ }^{2}$ (B)
}

Received: 20 June 2018 / Accepted: 22 September 2018/ Published online: 3 October 2018

(C) The Author(s) 2018

\begin{abstract}
Molten-salt-based nanofluids and ionic-liquid-based nanofluids are developed for thermal storage and heat transfer at relatively high temperatures, in the past few years. Preparation and stabilization techniques are briefly introduced firstly, and then, thermal properties, e.g., specific heat, thermal conductivity and viscosity, are summarized and discussed in detail. The properties are not only affected by the characteristics of nanomaterials and base fluids, but also affected by the synthesis method, such as the sonication intensity and duration. Some of the thermophysical property data are still incomplete, especially the thermal conductivity of molten-salt-based nanofluids, and properties of ionic-liquid-based nanofluids at high temperatures. While several literature works show that the Krieger-Dougherty model can well predict the viscosity, no general models for thermal conductivity and specific heat have been developed yet for both types of nanofluids.
\end{abstract}

Keywords Nanofluid $\cdot$ Molten salt $\cdot$ Ionic liquid $\cdot$ Medium-to-high temperature $\cdot$ Thermal properties

\section{List of symbols}

\section{Latin symbols}

$C_{\mathrm{p}} \quad$ Specific heat $\left(\mathrm{J} \mathrm{g}^{-1} \mathrm{~K}^{-1}\right)$

$H \quad$ Height of nanorod (nm)

$l \quad$ Inter-particle distance (nm)

$R \quad$ Particle radius $(\mathrm{nm})$

$T \quad$ Temperature (K)

$t \quad$ Interfacial layer (nm)

\section{Greek letters}

$\beta \quad$ Ratio of nanolayer thickness to the particle radius

[ $\eta]$ Intrinsic viscosity

$\lambda$ Thermal conductivity $\left(\mathrm{W} \mathrm{m}^{-1} \mathrm{~K}^{-1}\right)$

$\rho \quad$ Density $\left(\mathrm{kg} \mathrm{m}^{-3}\right)$

$\varphi \quad$ Volume fraction

\section{Bingxi Li}

libx@hit.edu.cn

$\triangle$ Bengt Sundén

bengt.sunden@energy.lth.se

1 School of Energy Science and Engineering, Harbin Institute of Technology, Harbin 150001, China

2 Department of Energy Sciences, Lund University, 22100 Lund, Sweden

\section{Subscripts \\ bf Base fluid \\ lr Interfacial layer \\ nf Nanofluid \\ np Nanoparticle \\ $\mathrm{x} \quad x$-axis \\ $\mathrm{z} \quad z$-axis}

\begin{tabular}{ll}
\multicolumn{2}{l}{ Abbreviations } \\
CB & Carbon black \\
EG & Ethylene glycol \\
EO & Engine oil \\
GE & Graphene \\
IL & Ionic liquid \\
ILBNF & Ionic-liquid-based nanofluid \\
mass & Mass concentration \\
MSBNF & Molten-salt-based nanofluid \\
MWCNT & Multi-walled carbon nanotubes \\
NF & Nanofluid \\
NP & Nanoparticle \\
SWCNT & Single-walled carbon nanotube \\
vol & Volume concentration
\end{tabular}




\section{Introduction}

Nanofluids (NFs) have been widely investigated in the last decades. However, they were firstly proposed by Choi and Eastman [1]. They are solid-liquid two-phase systems where the nanosized particles $(1-100 \mathrm{~nm})$ are dispersed into base liquids such as water, oil and ethylene glycol (EG), and physical methods are employed to improve the system stabilization. Due to the enhanced thermal properties, nanofluids are considered as a new generation of heat transfer and thermal storage fluids [2, 3]. Effects of the base fluids, particle materials, nanoparticle (NP) size, concentrations and morphology on the thermophysical properties have been reviewed by some studies [4-7].

Excellent enhancements on thermal conductivity $(\lambda)$ have been reported by many works [8-12]. Masuda et al. [8] measured a $30 \%$ increase in thermal conductivity by 4.3 vol\% $\mathrm{Al}_{2} \mathrm{O}_{3}$-water NFs with 13 -nm average diameter particles. Eastman et al. showed that the $\lambda$ can be improved by $60 \%$ in 5 vol\% $\mathrm{CuO}-$ water NFs [9] and by $40 \%$ increase of $0.3 \mathrm{vol} \% \mathrm{Cu}-\mathrm{EG} \mathrm{NF}$ with $10 \mathrm{~nm}$ diameter [10]. Moghadassi et al. [11] reported a 50\% increase in $\lambda$ of $5 \mathrm{vol} \% \mathrm{CuO}-$ monoethylene glycol and CuO-paraffin NFs. Murshed et al. [12] observed a $27 \%$ increase in 4 vol\% $\mathrm{TiO}_{2}$-water NFs with 15-nm-diameter NPs and a $20 \%$ increase for $\mathrm{Al}_{2} \mathrm{O}_{3}$-water NFs. However, most of the extremely high enhancements cannot be repeated by others. In 2009, a worldwide study was organized by the International Nanofluid Property Benchmark Exercise (INPBE). Over 30 laboratories around the world tested the same NFs using the same or different measurement methods. In fact, the experimental data did not show prominent increases on $\lambda$ [13]. Recently, hybrid nanofluids have been proposed. These have nanoparticles composed by two or more different nanomaterials. In this case, they can possess the common characteristics of the composite materials and may obtain further heat transfer enhancement with augmented thermal conductivity [14]. However, stability is one of the biggest challenges for hybrid nanofluids, due to the larger molecular mass and the surface charge of the two different materials [15]. However, most pervious works focused on water-based [16-18], EG-based [19-21] and engine oil (EO)-based [22-24] NFs, and these are considered as traditional NFs. The water-based and EG-based nanofluids can be only used below $100{ }^{\circ} \mathrm{C}$ and $190{ }^{\circ} \mathrm{C}$ at atmospheric pressure, respectively. The EO-based nanofluids can be used up to $400{ }^{\circ} \mathrm{C}$, but most additives and stabilizing agents cannot withstand temperatures as high as $60{ }^{\circ} \mathrm{C}$ [25]. Therefore, the surface modification method is employed for oil-based nanofluids [26], which leads to a high manufacturing cost.
Many industrial applications require the working fluids at medium (100-400 $\left.{ }^{\circ} \mathrm{C}\right)$ or even high temperatures $\left(>400{ }^{\circ} \mathrm{C}\right)$. For example, the operating temperature of working fluids in the heat collector of concentrated solar power (CSP) is usually higher than $300{ }^{\circ} \mathrm{C}$ and that of thermal storage fluids in CSP even can reach up to $550{ }^{\circ} \mathrm{C}$ $[27,28]$. Due to the low cost and thermal stability, the molten salts are usually used in the CSP, but the low heat transfer rate of molten salt blocks its CSP promotion. Based on this, the silica NPs added into inorganic salt $\left(\mathrm{Li}_{2} \mathrm{CO}_{3}: \mathrm{K}_{2} \mathrm{CO}_{3} 62: 38 \mathrm{~mol}\right)$ were firstly proposed by Shin and Banerjee [29]. They found that the specific heat $\left(C_{\mathrm{p}}\right)$ can be enhanced by up to $25 \%$, by only 1 mass $\%$ of silica NPs of 1-20 nm size. More importantly, some molten-saltbased nanofluids (MSBNFs) can be stable without any additives. According to this idea, some follow-up studies on MSBNFs were performed and found that the enhancement of $C_{\mathrm{p}}$ in the solid phase is higher than that in the liquid phase.

An ionic liquid (IL) is a special kind of molten salt with a melting point below $100{ }^{\circ} \mathrm{C}$, which is also called roomtemperature molten salt (melting point of traditional molten salt is above $100{ }^{\circ} \mathrm{C}$ ) [30]. The ILs attract a lot of attention due to the extremely low vapor pressure and thermal stability, and the properties can be designed by a suitable selection of the cation and anion. With a wide range of fluid working temperature from room temperature, it is promising for employment as a heat transfer fluid rather than traditional molten salt. Incorporation of nanosized particles with ILs was firstly proposed by Castro et al. [31], which also surfactant-free [32], and proved that it can improve the $\lambda$. The enhancement of $\lambda$ increases with the increase in temperature and mass fraction of NPs. The maximum enhancement can reach $25 \%$ for graphene (GE)[HMIM][BF4] system at $200{ }^{\circ} \mathrm{C}$ as found by Liu et al. [33].

This article aims at an overview of the molten-salt-based nanofluids (MSBNFs) and ionic-liquid-based nanofluids (ILBNFs), which can be used at medium-to-high temperatures. The review will focus mainly on their thermal properties $\left(C_{\mathrm{p}}, \lambda\right.$ and viscosity). The comparison of the experimental data for different NPs and base fluids should provide some guidance for future research.

\section{Nanofluid preparation and stability}

\section{Nanofluid preparation}

There are two main methods to prepare NFs: two-step method and one-step method [34]. The two-step method is the most widely used, and the NPs are firstly dried as powders and then dispersed into the base fluid. Ultrasonic vibration, surfactants or other techniques are commonly 
used to disperse the particles and reduce the agglomeration. The two-step method is the most economic method to produce NFs in large scale, and nanopowders can be supplied in plenty quantities by several companies. However, there are also some shortcomings of the two-step method such as particle agglomeration during drying, storage and transportation of NPs and dispersion of NPs in the base fluids. Wang et al. [35] found that the sonication time has a big influence on the properties of suspensions. Too short sonication time causes a high viscosity $(\mu)$, especially for high volume fractions, while too long sonication time can reduce the $\mu$ but lessen the enhancement of $\lambda$. There exists no definite guidance for various kinds of NFs. In addition, surfactants may cause a decrease in $\lambda$, and the functionality might be changed under relatively high temperatures or produce foam [36].

In order to improve the stability and reduce the agglomeration, the one-step method was developed [37]. It is a process that simultaneously makes NPs and disperses the NPs into base fluids, for which the NPs are directly prepared by physical vapor deposition or a liquid chemical method [10]. In the single-step method, the processes of drying, storage, transportation and dispersion of NPs are avoided, so the agglomeration of NPs is minimized and the stability of the fluids is increased. To prevent the oxidation of metallic particles, the single-step method is always preferable for synthesizing NFs containing metal particles. The main disadvantage of the one-step method is that the cost of physical vapor deposition method to prepare the NPs is too high as well as hard to be utilized in large scale and can only be used on low vapor pressure base fluids. Using the liquid chemical method to prepare the NPs may leave residual reactants in NFs due to the incomplete reaction or stabilization and it is hard to be eliminated completely. The molten-salt- and ionic-liquid-based NFs are difficult to synthesize by this method.

Many molten-salt-based and ionic-liquid-based NFs are synthesized by the two-step method or improved two-step method [38]. Fukushima et al. [39] found that imidazolium-ion-based ionic liquids were excellent dispersants for carbon nanotubes, which could reproduce stabilized NFs by sonification or grinding the suspensions. This method was also employed by Nieto de Castro et al. [31] to synthesize NFs with multi-walled carbon nanotubes (MWCNTs) in ionic liquid ([C4mim][PF6]). Paul et al. [40] dispersed the $\mathrm{Al}_{2} \mathrm{O}_{3}$ into four kinds of ionic liquids ([C4mim][NTf2], [C4mmim][NTf2], [C4mpyrr][NTf2] and [N4111][NTf2]) using a vortex mixer to produce NFs. An improved two-step method was widely used for moltensalt-based NFs, which mainly includes four basic steps to complete the synthesize process [36]: firstly, mixing the inorganic salt and nanopowders; secondly, adding a certain quantity of distilled water to dissolve the salt; thirdly, using the ultrasonic power to break the agglomerations; and finally, evaporating the water and obtaining the final sample. The above-described process is shown in Fig. 1.

\section{Stability}

Due to the high surface area and surface activity, NPs tend to agglomerate by the van der Waals attraction force. The agglomeration may result in settlement and clogging in the microchannels and also have a negative effect on the $\lambda$ enhancement [34]. Thus, the long-term stability of NFs is a precondition for its analysis and utilization. There are some traditional techniques which can be used to change the surface state of NPs in order to prevent the agglomeration and obtain a stable NF.
Fig. 1 The method for preparing the molten-salt-based nanofluid. Reprinted from [22] with the permission from Elsevier

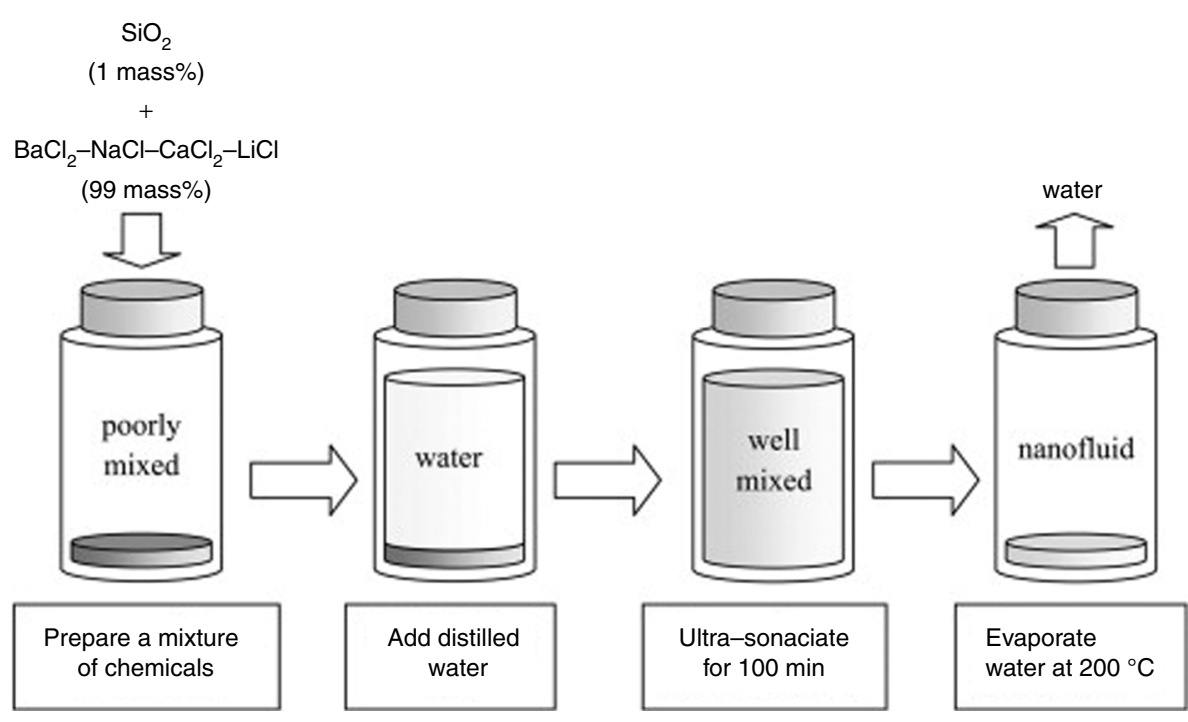




\section{Addition of surfactants}

This is the most common method, easy and economic, to avoid sedimentation of NPs. Surfactants can adhere to the NPs and change its wettability and thus improve the continuity between the NPs and fluids. The surfactants are divided into four classes [34, 41]: nonionic surfactants without charge groups in its head, anionic surfactants with negatively charged head groups, cationic surfactants with positively charged head groups and amphoteric surfactants with zwitterionic head groups. However, the dispersants between the NPs and fluids can enlarge the thermal resistance, limit the enhancement of $\lambda$ and increase the $\mu$. More importantly, the most surfactants cannot withstand temperatures as high as $60{ }^{\circ} \mathrm{C}[25]$.

\section{Surface modification techniques}

It is also called surfactant-free method. Through chemical reaction, the surface of NPs can be modified by functionalization. Using the modified NPs, NFs can keep long-term stability. This can avoid the loss of $\lambda$ and no increase on $\mu$. The disadvantage is that a high accuracy for chemical reactions is needed, and it is hard to control the reaction process. This method is mainly used in the biomedical field and, still at the laboratory level, is difficult to obtain at large scale [42].

\section{$\mathrm{PH}$ control}

The stability of NFs is directly related to the electrokinetic properties. The strong repulsive forces can be obtained by PH control, resulting in a well-dispersed suspension. The isoelectric point (IEP) is defined as the value of $\mathrm{PH}$ at which a particular molecule carries no net electric charge, or hydration forces are negligible [43]. The NF is unstable when the PH value is nearly equal to the IEP, and different NFs have different IEPs. The suitable PH values for alumina, copper and graphite-water suspensions are around 8.0, 9.5 and 2.0, respectively [44]. The PH for the IEP also changes with temperature variation [45]. This method also has the limitation that the PH of NFs must be around 7 , because the acidic and alkaline fluid may corrode the heat transfer surface [46].

\section{Ultrasonic vibration}

This is the most commonly used physical method, different from the aforementioned three methods of chemical treatment. This method does not change the surface properties of NPs, but only break down the agglomerations. It seems simple to be applied in industry, but the suspensions tend to agglomerate and clog after a period of time. Some strong disturbances can be produced by the sudden expanding and converging surfaces such as fluid acceleration, fluid impact on the wall, fluid pulsation and high shear flow (secondary and rotation flow) [47-49]. Due to the strong effect of the ultrasonic time and intensity on the properties of NFs, the method needs to be deeply studied [35].

Due to the high-temperature preparation process and application environment, the method of additives can hardly be used, and the ultrasonic vibration is still the most common method to maintain the stability of suspensions.

\section{Theoretical model}

\section{Theoretical model for traditional NFs}

There are many review works which have summarized the theoretical models to predict thermophysical properties ( $\rho$, $\lambda, C_{\mathrm{p}}$ and $\mu$ ) of traditional NFs [50-54]. In this work, the dozens of models are not repeated again, but several representative models are presented instead. The density of the nanofluid can be directly calculated by the mixing theory [55] as follows:

$\rho_{\mathrm{nf}}=\frac{m_{\mathrm{np}}+m_{\mathrm{bf}}}{V_{\mathrm{np}}+V_{\mathrm{bf}}}=\frac{\rho_{\mathrm{np}} V_{\mathrm{np}}+\rho_{\mathrm{bf}} V_{\mathrm{bf}}}{V_{\mathrm{np}}+V_{\mathrm{bf}}}=\varphi \rho_{\mathrm{np}}+(1-\varphi) \rho_{\mathrm{bf}}$

where $\varphi$ is the nanoparticle volume concentration. Subscripts nf, np and bf indicate the nanofluid, nanoparticle and base fluid, respectively.

The Maxwell model [56] is the first one to calculate $\lambda$ of low-volume-fraction solid-liquid suspensions. It is mainly used on spherical particles; based on this, several extended Maxwell models were developed [57-59]. However, these models only considered the effect of volume fraction, and the influences of NPs shape, size, distribution, particleparticle interaction, and temperature are little considered. They are more like empirical correlations and lacking description of potential mechanisms. Later, a series of theories on enhancement of $\lambda$ were put forward, including (1) Brownian motion, (2) clustering, (3) nanolayer, (4) ballistic transport and nonlocal effect, (5) thermophoretic effect and (6) near-field radiation. The first three theories were widely studied by scholars. Xuan et al. [60] proposed a model to include the Brownian motion effect, fluid temperature and the structure of NP clusters in $\lambda$. Yu et al. [61] proposed a modified Maxwell model by considering the nanolayer theory to calculate $\lambda$ of NFs. Yamada et al. [62] proposed a model for CNT NFs and considered the effect of radius and length of CNTs. Yang et al. [63] proposed a thermal conductivity model for nanorod NFs by allocating the proportion of two intermediate thermal 
conductivities in the axial and radial directions according to the surface area ratio of the flanks and ends of the nanorod, and the interfacial layer was also considered in this model. The above models to predict $\lambda$ are shown in Table 1.

Pak et al. [64] firstly proposed a model to measure specific heat of NFs in 1998. A modified model by Xuan and Roetzel [65] was given in 2000, which has been validated by Hanley et al. $\left(\mathrm{SiO}_{2}, \mathrm{Al}_{2} \mathrm{O}_{3}\right.$ and $\mathrm{CO}_{2}$-water) [66] and Murshed (Al-EG, $\mathrm{TiO}_{2}-\mathrm{EG}$ and $\left.\mathrm{Al}-\mathrm{EO}\right)$ [67]. The results show that the Xuan and Roetzel model can fit well with the experimental data. A new correlation was developed by Vajjha et al. [68], which considered the effect of temperature. However, the coefficients in the model are changed with different nanoparticles and base fluids. Pakdaman et al. [69] developed a model to predict $C_{\mathrm{p}}$ of
MWCNT-heat transfer oil and considered the temperature ranging from 313 to $343 \mathrm{~K}$. Sekhar et al. [70] proposed a correlation based on 81 experimental data of water-based NFs from the published works. This model not only considered the effect of temperature but also considered the particle size. The above models to predict $C_{\mathrm{p}}$ are shown in Table 2.

A summary of $\mu$ prediction models is shown in Table 3 . The most classic model for $\mu$ prediction of NFs is the Einstein model [71]. It can only be used at low volume fractions below 2 vol\%. Various modified Einstein models have been proposed by many researchers. Guo et al. [72] considered the particle size effect and found that the smaller particle size induces higher $\mu$. Graham et al. [73] considered both the particle radius and inter-particle distance. Krieger et al. [74] proposed a correlation to fit for

Table 1 Brief summary of thermal conductivity prediction models

\begin{tabular}{|c|c|c|}
\hline Models & Thermal conductivity & Comments \\
\hline $\begin{array}{l}\text { Maxwell } \\
{[56]}\end{array}$ & $k_{\mathrm{nf}}=k_{\mathrm{bf}} \frac{k_{\mathrm{np}}+2 k_{\mathrm{bf}}+2 \varphi\left(k_{\mathrm{np}}-k_{\mathrm{bf}}\right)}{k_{\mathrm{np}}+2 k_{\mathrm{bf}}-\varphi\left(k_{\mathrm{np}}-k_{\mathrm{bf}}\right)}$ & $\begin{array}{l}\text { First model to calculate the thermal conductivity of solid-liquid suspensions. } \\
\text { For hard spherical particles without particle interactions and for low volume } \\
\text { fractions }\end{array}$ \\
\hline $\begin{array}{l}\text { Xuan et al. } \\
{[60]}\end{array}$ & $k_{\mathrm{nf}}=k_{\mathrm{bf}} \frac{k_{\mathrm{np}}+2 k_{\mathrm{bf}}+2 \varphi\left(k_{\mathrm{np}}-k_{\mathrm{bf}}\right)}{k_{\mathrm{np}}+2 k_{\mathrm{bf}}-\varphi\left(k_{\mathrm{np}}-k_{\mathrm{bf}}\right)}+\frac{1}{2} \rho_{\mathrm{np}} C_{\mathrm{np}} \varphi \sqrt{\frac{K_{\mathrm{B}} T}{3 \pi \mu_{\mathrm{bf}} R_{\mathrm{cl}}}}$ & $\begin{array}{l}\text { According to the Maxwell model, this model considered Brownian motion and } \\
\text { structure of NPs, including temperature, viscosity and size of NPs }\end{array}$ \\
\hline $\begin{array}{l}\text { Yu and } \\
\text { Choi [61] }\end{array}$ & $k_{\mathrm{nf}}=k_{\mathrm{bf}} \frac{k_{\mathrm{np}}+2 k_{\mathrm{bf}}+2 \varphi\left(k_{\mathrm{np}}-k_{\mathrm{bf}}\right) \beta^{3}}{k_{\mathrm{np}}+2 k_{\mathrm{bf}}-\varphi\left(k_{\mathrm{np}}-k_{\mathrm{bf}}\right) \beta^{3}}$ & $\begin{array}{l}\text { Also according to the Maxwell model, this model considered the influence of } \\
\text { the nanolayer surrounding the particles }\end{array}$ \\
\hline $\begin{array}{l}\text { Yamada } \\
\text { and Ota } \\
{[62]}\end{array}$ & $k_{\mathrm{nf}}=k_{\mathrm{bf}} \frac{1+\frac{k_{\mathrm{b}} H}{k_{\mathrm{np}} R} \varphi^{0.2}+\left(1-\frac{k_{\mathrm{bf}}}{k_{\mathrm{np}}}\right) \varphi \frac{H}{R} \varphi^{0.2}}{1+\frac{k_{\mathrm{ff}} H}{k_{\mathrm{np}} R} \varphi^{0.2}-\left(1-\frac{k_{\mathrm{b}}}{k_{\mathrm{np}}}\right) \varphi}$ & $\begin{array}{l}\text { This model is proposed for CNTs which include the effect of radius and length } \\
\text { of CNTs }\end{array}$ \\
\hline $\begin{array}{l}\text { Yang et al. } \\
{[63]}\end{array}$ & $\begin{aligned} k_{\mathrm{nf}}= & \frac{(H+2 t) k_{\mathrm{nf}} \_\mathrm{x}}{H+R+3 T}+(R+t) k_{\mathrm{nf} \_z} \\
k_{\mathrm{nf} \_\mathrm{x}}= & \frac{A \varphi k_{\mathrm{np}}+(\alpha \cdot B+\beta C) \varphi_{\mathrm{np}} k_{\mathrm{rl}}+(1+\alpha+\beta) \varphi_{\mathrm{np}} k_{\mathrm{bf}}-k_{\mathrm{bf}}}{A \varphi_{\mathrm{np}}+(\alpha B+\beta C) \varphi_{\mathrm{np}}+(1+\alpha+\beta) \varphi_{\mathrm{np}}-1} \\
k_{\mathrm{nf} \_\mathrm{z}}= & \frac{H+2 t}{H} \varphi_{\mathrm{np}}\left(\frac{(H+2 t) k_{\mathrm{lr}} k_{\mathrm{np}}}{2 t k_{\mathrm{np}}+H k_{\mathrm{lr}}}+\alpha k_{\mathrm{lr}}\right)+k_{\mathrm{bf}} \\
& -\frac{(H+2 t)(1+\alpha) k_{\mathrm{bf}} \varphi_{\mathrm{np}}}{H}\end{aligned}$ & $\begin{array}{l}\text { This model is built for nanorods, by allocating the proportion in axial and radial } \\
\text { directions. The shape and size, also the interfacial layer of the nanorod, are } \\
\text { considered }\end{array}$ \\
\hline
\end{tabular}

Table 2 Brief summary of specific heat prediction models

\begin{tabular}{|c|c|c|}
\hline Models & Specific heat & Comments \\
\hline $\begin{array}{l}\text { Pak and Cho } \\
\text { [64] }\end{array}$ & $C_{\mathrm{p}_{\mathrm{nf}}}=(1-\varphi) C_{\mathrm{p}_{\mathrm{bf}}}+\varphi C_{\mathrm{p}_{\mathrm{np}}}$ & $\begin{array}{l}\text { This is the first model to calculate the specific heat of NFs by } \\
\text { considering the volume concentration of NPs }\end{array}$ \\
\hline $\begin{array}{l}\text { Xuan and } \\
\text { Roetzel } \\
{[65]}\end{array}$ & $C_{\mathrm{p}_{\mathrm{nf}}}=\frac{\varphi \rho_{\mathrm{np}} C_{\mathrm{pnp}}+(1-\varphi) \rho_{\mathrm{bf}} C_{\mathrm{pbf}}}{\varphi \rho_{\mathrm{np}}+(1-\varphi) \rho_{\mathrm{bf}}}$ & $\begin{array}{l}\text { A modified model based on the Pak-Cho model according to the heat } \\
\text { equilibrium mechanism }\end{array}$ \\
\hline $\begin{array}{c}\text { Vajjha and } \\
\text { Das [68] }\end{array}$ & $C_{\mathrm{P}_{\mathrm{nf}}} / C_{\mathrm{p}_{\mathrm{bf}}}=\frac{\left[(A \times T)+B \times C_{\mathrm{p}_{\mathrm{bf}}}\right]}{C+\varphi}$ & $\begin{array}{l}\text { This correlation is developed as a function of volume fraction and } \\
\text { temperature. The coefficients } A, B \text { and } C \text { vary with the different NPs }\end{array}$ \\
\hline $\begin{array}{l}\text { Pakdaman } \\
\text { et al. [69] }\end{array}$ & $\frac{C_{\mathrm{p}_{\mathrm{bf}}}-C_{\mathrm{p}_{\mathrm{nf}}}}{C_{\mathrm{P}_{\mathrm{bf}}}}=(0.0128 \times T+1.8382) \varphi^{0.4779}$ & $\begin{array}{l}\text { This correlation is developed based on the least square method, for } \\
\text { MWCNT-oil NFs. With a weight concentration less than } 0.004 \text { and } \\
\text { temperature ranging from } 313 \text { to } 343 \mathrm{~K}\end{array}$ \\
\hline $\begin{array}{l}\text { Sekhar and } \\
\text { Sharma } \\
{[70]}\end{array}$ & $C_{\mathrm{p}_{\mathrm{nf}}}=0.8429\left(1+\frac{T}{50}\right)^{-0.3037}\left(1+\frac{R_{\mathrm{p}}}{50}\right)^{0.4167}\left(1+\frac{\varphi}{100}\right)^{2.272}$ & $\begin{array}{l}\text { This regression correlation is developed based on } 81 \text { experimental data } \\
\text { from the literature, with the following ranges: volume fraction } \\
(0.01-4.00 \%) \text {, temperature }(293-323 \mathrm{~K}) \text { and particle diameter } \\
(15-50 \mathrm{~nm})\end{array}$ \\
\hline
\end{tabular}


Table 3 Brief summary of viscosity prediction models

\begin{tabular}{|c|c|c|}
\hline Models & Viscosity & Comments \\
\hline Einstein [71] & $\mu_{\mathrm{nf}}=\mu_{\mathrm{bf}}(1+2.5 \varphi)$ & $\begin{array}{l}\text { The most classic and pioneer model for NP concentrations below } 2 \text { vol\%. This } \\
\text { model only applies for hard spherical particles without particle interactions }\end{array}$ \\
\hline Guo et al. [72] & $\mu_{\mathrm{nf}}=\mu_{\mathrm{bf}}\left(1+2.5 \varphi+6.5 \varphi^{2}\right)(1+350 \varphi / R)$ & $\begin{array}{l}\text { This model considers the effect of particle size and found that the smaller } \\
\text { particle size will induce a higher viscosity in NFs }\end{array}$ \\
\hline Graham [73] & $\mu_{\mathrm{nf}}=\mu_{\mathrm{bf}}\left(1+2.5 \varphi+\frac{4.5}{(l / R)(2+l / R)(1+l / R)^{2}}\right)$ & $\begin{array}{l}\text { According to the Einstein model, this model considers the particle radius and } \\
\text { inter-particle distance }\end{array}$ \\
\hline $\begin{array}{l}\text { Krieger and } \\
\text { Dougherty [74] }\end{array}$ & $\mu_{\mathrm{nf}}=\mu_{\mathrm{bf}}\left(1-\left(\varphi / \varphi_{\mathrm{m}}\right)\right)^{[\eta] \varphi_{\mathrm{m}}}$ & $\begin{array}{l}\text { This model is proposed to fit for a full coverage of particle contents, } \\
\text { considering the difference of viscosity at different shear rates }\end{array}$ \\
\hline Chen et al. [75] & $\mu_{\mathrm{nf}}=\mu_{\mathrm{bf}}\left(1-\left(\varphi_{\mathrm{cl}} / \varphi_{\mathrm{m}}\right)\right)^{[\eta] \varphi_{\mathrm{m}}}$ & $\begin{array}{l}\text { A modified Krieger-Dougherty model considering the packing volume } \\
\text { fraction of the imaginary sphere containing cluster }\end{array}$ \\
\hline $\begin{array}{l}\text { Selvakumarand } \\
\text { Dhinakaran } \\
\text { [76] }\end{array}$ & $\begin{array}{l}\mu_{\mathrm{nf}}=\mu_{\mathrm{bf}}\left(1-\left(\varphi_{\mathrm{ecl}} / \varphi_{\mathrm{m}}\right)\right)^{[\eta] \varphi_{\mathrm{m}}} \\
\varphi_{\mathrm{ecl}}=\varphi_{\mathrm{cl}}(1+\beta)^{3}\end{array}$ & $\begin{array}{l}\text { An upgraded model of the Chen et al. model, considering the interfacial layers } \\
\text { surrounding the cluster }\end{array}$ \\
\hline $\begin{array}{l}\text { White and } \\
\text { Corfield [77] }\end{array}$ & $\ln \frac{\mu_{\mathrm{nf}}}{\mu_{0}} \approx a+b\left(\frac{T_{0}}{T}\right)+c\left(\frac{T_{0}}{T}\right)^{2}$ & $\begin{array}{l}\text { This model found that temperature is an essential parameter to the viscosity, } \\
\text { rarely considered by other models }\end{array}$ \\
\hline
\end{tabular}

full coverage of particle contents and have considered the difference of $\mu$ at different shear rates. A modified KriegerDougherty model was presented by Chen et al. [75], who considered the packing volume fraction of an imaginary sphere containing clusters based on the fractal theory. Recently, a newly upgraded model based on the Chen et al. model was put forward by Selvakumar et al. [76] by considering interfacial layers surrounding the clusters. In addition, White et al. [77] found that temperature has a big influence on $\mu$ but few models have considered it.

Although many factors have been involved in the existing models, the prediction accuracy and application range are still limited, especially as some models can only predict the corresponding kinds of NFs.

\section{Experimental}

\section{Molten-salt-based nanofluid}

The molten salt and its related NFs are mainly used as high-temperature thermal storage fluids, and the $C_{\mathrm{p}}$ has been studied by many researchers. There is a common result that the specific heat of MSBNFs is increased by the NPs, which is opposite to the traditional NFs. Several published works on $C_{\mathrm{p}}$ of MSBNFs are summarized in Table 4.

Two kinds of eutectic molten salts $\left(60 \% \mathrm{NaNO}_{3}\right.$ $+40 \% \mathrm{KNO}_{3}$, and $62 \% \mathrm{Li}_{2} \mathrm{CO}_{3}+38 \% \mathrm{~K}_{2} \mathrm{CO}_{3}$ ) are mostly used as base fluids. The $C_{\mathrm{p}}$ for a temperature range from 250 to $420{ }^{\circ} \mathrm{C}$ (liquid phase) with various concentrations (0.5 mass\%, 1.0 mass\%, 1.5 mass $\%$ and 2.0 mass $\%$ ) of $\mathrm{SiO}_{2}$ NPs dispersed into the solar salt $\left(60 \% \mathrm{NaNO}_{3}\right.$ $\left.+40 \% \mathrm{KNO}_{3}\right)$ was studied by Andreu et al. [78]. The average enhancement of $C_{\mathrm{p}}$ is $3.41 \%, 25.03 \%, 2.00 \%$ and $3.69 \%$, respectively, with the increase in NPs mass fraction. Moreover, Chieruzzi et al. [79] also added the NPs $\left(\mathrm{SiO}_{2}, \mathrm{Al}_{2} \mathrm{O}_{3}, \mathrm{TiO}_{2}\right.$ and $\left.\mathrm{SiO}_{2}-\mathrm{Al}_{2} \mathrm{O}_{3}\right)$ into the solar salt, with three kinds of mass concentrations $(0.5,1.0$ and 1.5 mass $\%)$. They also found that the 1.0 mass $\%$ mass fraction is the optimal value for enhancement of $C_{\mathrm{p}}$. The effective order of specific heat enhancement is $\mathrm{SiO}_{2}-\mathrm{Al}_{2}$ $\mathrm{O}_{3}>\mathrm{Al}_{2} \mathrm{O}_{3}>\mathrm{SiO}_{2}>\mathrm{TiO}_{2}$, and for the small concentration $(0.5$ mass $\%)$ and $\mathrm{TiO}_{2}$ are side effects to the $C_{\mathrm{p}}$. In another work, Chieruzzi et al. [80] found that the screw rotation speed and mixing time have big influences on the specific heat, as shown in Table 5. The enhancement of $C_{\mathrm{p}}$ in the solid phase is much higher than in the liquid phase; the maximum enhancements are $52.1 \%$ and $18.6 \%$, respectively, with $\mathrm{SiO}_{2}-\mathrm{Al}_{2} \mathrm{O}_{3}$ NPs at the biggest screw rotation speed and mixing time (200 rpm-30 min).

For another widely used eutectic molten salt $\left(62 \% \mathrm{Li}_{2-}\right.$ $\mathrm{CO}_{3}+38 \% \mathrm{~K}_{2} \mathrm{CO}_{3}$ ), Tiznobaik et al. [81] dispersed $\mathrm{SiO}_{2}$ into molten salt and found that the particle size has little effect on the enhancement, and the growth rate for the solid phase is little higher than that for the liquid phase. $\mathrm{Al}_{2} \mathrm{O}_{3}$ was used by Shin et al. [82] and compared with the Tiznobaik et al.'s [81] data at the same NP size and concentration (10 $\mathrm{nm}$ and 1 mass $\%)$. The enhancement of $\mathrm{Al}_{2} \mathrm{O}_{3}$-based MSBNF is higher than $\mathrm{SiO}_{2}$-based MSBNF (32\% and 29\%). This result was also confirmed by Tiznobaik et al. [83] in 2015, and it was found that $\mathrm{Al}_{2}$ $\mathrm{O}_{3}>\mathrm{SiO}_{2}>\mathrm{MgO}$. Jo et al. [84] used the graphite NP; the enhancement of $C_{\mathrm{p}}$ was similar to $\mathrm{SiO}_{2}$-based MSBNF in the solid phase, but smaller than $\mathrm{SiO}_{2}$-based MSBNF in the liquid phase.

There are some special molten salts studied by Shin et al. [29] and Ho et al. [85], 


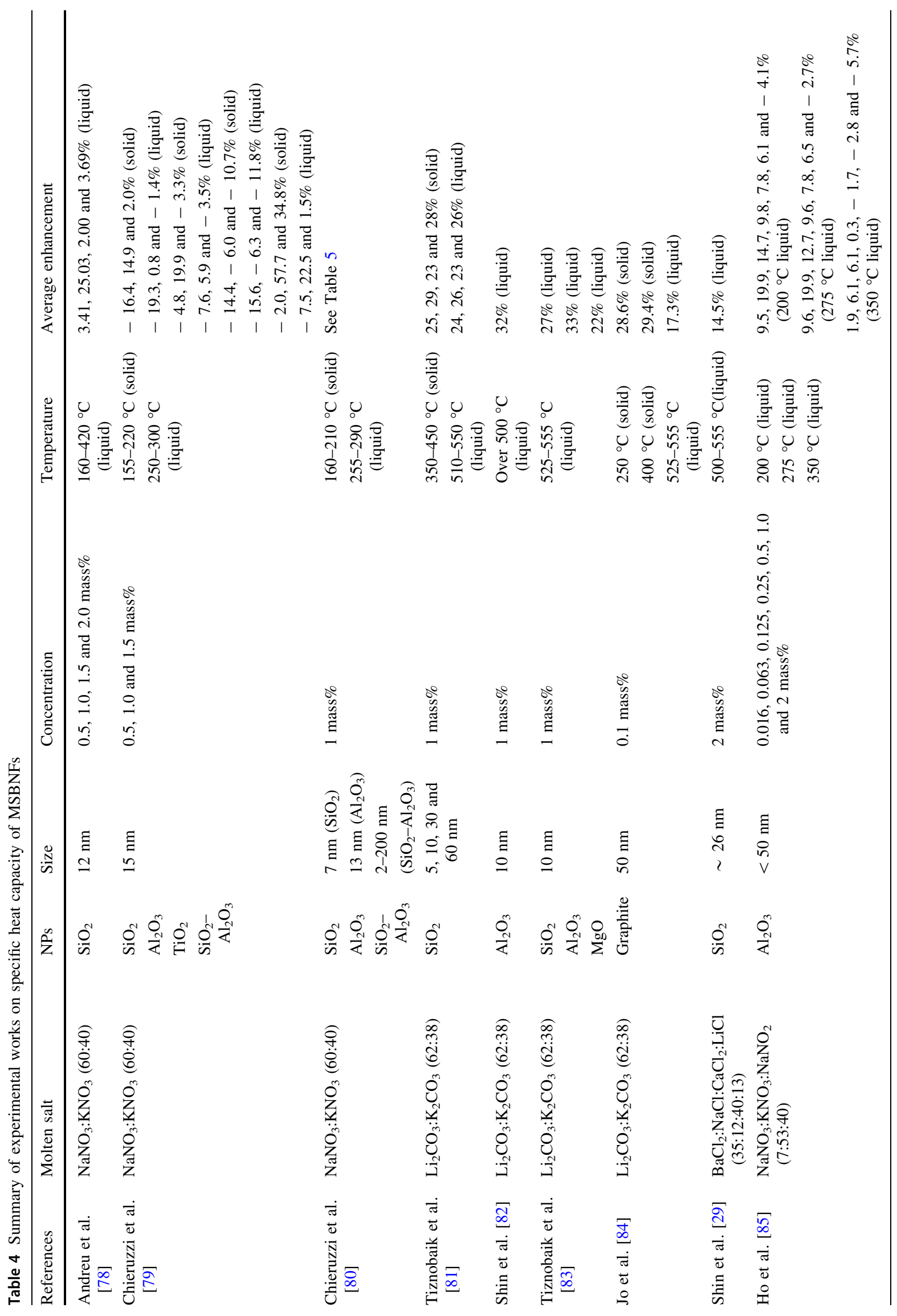


$\left(35 \% \mathrm{BaCl}_{2}+12 \% \mathrm{NaCl}+40 \% \mathrm{CaCl}_{2}+13 \% \mathrm{LiCl}\right.$ and $7 \% \mathrm{NaNO}_{3}+53 \% \mathrm{KNO}_{3}+40 \% \mathrm{NaNO}_{2}$ ). For a comprehensive comparison, the most effective order of $C_{\mathrm{p}}$ enhancement for $\mathrm{NPs}$ is $\mathrm{SiO}_{2}-\mathrm{Al}_{2} \mathrm{O}_{3}>\mathrm{Al}_{2} \mathrm{O}_{3}>\mathrm{SiO}_{2}$ $>\mathrm{GE}>\mathrm{MgO}>\mathrm{TiO}_{2}$. For the molten salt, the enhancement of $C_{\mathrm{p}}$ for $62 \% \mathrm{Li}_{2} \mathrm{CO}_{3}+38 \% \mathrm{~K}_{2} \mathrm{CO}_{3}$ is almost independent of the temperature variation. The experiment data for $60 \% \mathrm{NaNO}_{3}+40 \% \mathrm{KNO}_{3}$ and $7 \% \mathrm{NaNO}_{3}$ $+53 \% \mathrm{KNO}_{3}+40 \% \mathrm{NaNO}_{2}$ are very volatile with the temperature.

The researches on MSBNF mainly focused on the enhancement of specific heat, and works on $\lambda$ and $\mu$ marginally little published. The $\lambda$ measurement of $\mathrm{SiO}_{2}$ in molten salt of lithium carbonate and potassium carbonate $\left(62 \% \mathrm{Li}_{2} \mathrm{CO}_{3}+38 \% \mathrm{~K}_{2} \mathrm{CO}_{3}\right)$ was performed by Shin et al. [86], with the NPs size in 10-30 nm (1 mass\%). The enhancement of $\lambda$ for MSBNF was in the range of $37-47 \%$, at different temperatures. A big deviation between the experimental data and conventional models (HamiltonCrosser model and Maxwell-Garnett model) was observed, as shown in Fig. 2. Ueki et al. [87] tested $\lambda$ of silicon carbide NPs in heat transfer salt $\left(\mathrm{NaNO}_{2}: \mathrm{NaNO}_{3}: \mathrm{KNO}_{3}\right.$, 40:7:53 mass \%). An increase of $13 \%$ was found with the particle volume fraction of $0.72 \mathrm{vol} \%$, at $200{ }^{\circ} \mathrm{C}$. The measured value was located between the theoretical upper and lower limits of NFs $\lambda$.

Viscosity is an important rheological property which determines the flow resistance. Literature works have considered the effect of NPs concentration and temperature. As a non-Newtonian fluid of MSBNF, the shear rate is also considered widely. Lasfargues et al. [88] added 0.1 mass $\% \mathrm{CuO}$ into the solar salt, which led to an increase of $10.8 \%, 4.7 \%, 12.9 \%, 18.3 \%$ and $14.9 \%$ at 250, 300, 350, 400 and $450{ }^{\circ} \mathrm{C}$, respectively. However, $\mu$ decreases sharply with an increase in temperature and shear stress, which

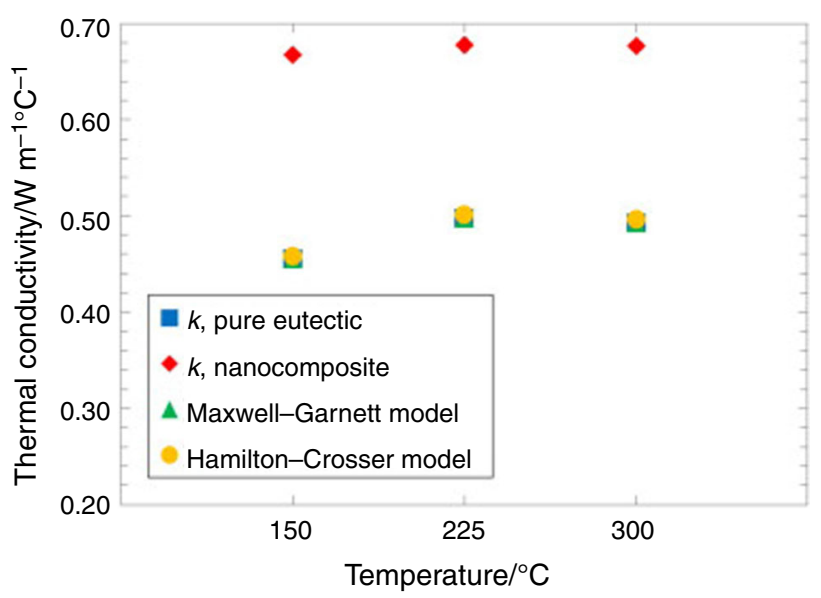

Fig. 2 Comparison of thermal conductivity values of the MSBNF (1 mass $\% \quad \mathrm{SiO}_{2}$ and $62 \% \mathrm{Li}_{2} \mathrm{CO}_{3}+38 \% \mathrm{~K}_{2} \mathrm{CO}_{3}$ ) and theoretical models. Reprinted from [74] with the permission from Elsevier is very meaningful for applications. Jung et al. [89] showed that the pure solar salt demonstrates a Newtonian behavior and the MSBNF ( $\mathrm{SiO}_{2}$-solar salt) at different temperatures (300, 350 and $400{ }^{\circ} \mathrm{C}$ ) presented non-Newtonian behavior (shear thickening behavior). For 0.5 mass $\%$ and 1.0 mass $\%$ MSBNFs, the maximum increases in $\mu$ values are $64.8 \%$ and $55.9 \%$ (at $400{ }^{\circ} \mathrm{C}$ ), $51.6 \%$ and $67.7 \%$ (at $350{ }^{\circ} \mathrm{C}$ ), $38.9 \%$ and $56 \%$ (at $300{ }^{\circ} \mathrm{C}$ ), respectively. This indicates that the enhancement of $\mu$ is increased with both mass concentration and temperature. The $\mu$ values can be predicted well by the Krieger-Dougherty model [74]. Experimental measurements of $\mu$ of MSBNF with multi-walled carbon nanotubes $\left(\mathrm{Li}_{2} \mathrm{CO}_{3}: \mathrm{K}_{2} \mathrm{CO}_{3}, 62: 38\right.$ molar) were taken by Byeongnam et al. [90], with a wide range of shear rate and nanotube concentrations (1 mass $\%, 2$ mass $\%$ and 5 mass $\%$ ). The increase in the $\mu$ values was $11 \%, 93 \%$ and $1130 \%$ corresponding to the mass concentrations of 1 mass $\%, 2$ mass $\%$ and 5 mass $\%$, respectively, with the fixed temperature of $550{ }^{\circ} \mathrm{C}$ and $1000 \mathrm{~s}^{-1}$ shear rate. The experimental data are also well within predictions of the Krieger-Dougherty model, as shown in Fig. 3a.

Recently, several experimental works have confirmed that the MSBNFs can improve the convection heat transfer coefficient significantly. Ho and Pan [91] tested the performances of laminar convective heat transfer of MSBNFs with various concentrations (0.016 mass $\%, 0.063$ mass $\%$, 0.125 mass $\%$ and 0.25 mass $\%$ ) of $\mathrm{Al}_{2} \mathrm{O}_{3}$ nanoparticles $\left(7 \% \mathrm{NaNO}_{3}+53 \% \mathrm{KNO}_{3}+40 \% \mathrm{NaNO}_{2}\right)$, and obtained enhancements of $6.9,9.2,7.6$ and $11.6 \%$ of the mean Nusselt number, compared with the pure molten salt flow, respectively. Bellos et al. [92] dispersed $\mathrm{CuO}$ into molten salt $\left(60 \% \mathrm{NaNO}_{3}+40 \% \mathrm{KNO}_{3}\right)$ and obtained a $13 \%$ mean increase in heat transfer at the temperature range of $550-850 \mathrm{~K}$ with 6 vol\% concentration. The maximum enhancement came up to $13.9 \%$ at $550 \mathrm{~K}$.

\section{Ionic-liquid-based nanofluid}

Ionic-liquid-based nanofluids (ILBNFs) are expected to be used at medium-to-high temperature conditions, but most published works measured its properties below $100{ }^{\circ} \mathrm{C}$. A summary of experimental works on thermophysical properties $\left(\lambda, C_{\mathrm{p}}\right.$ and $\left.\mu\right)$ of ILBNFs is given in Table 6 .

Thermal conductivity of ILBNFs attracts most attention. Several experimental data below $80{ }^{\circ} \mathrm{C}$, with different kinds of ILs and NPs, are summarized in Fig. 4. Nieto de Castro et al. [93] and Paul et al. [94] found that the enhancement ratio of $\lambda$ is nearly independent of the temperature, and it increases clearly with the increase in NP mass fraction. From Castro's work, it can be seen that the effective order to increase $\lambda$ for ILs is: 


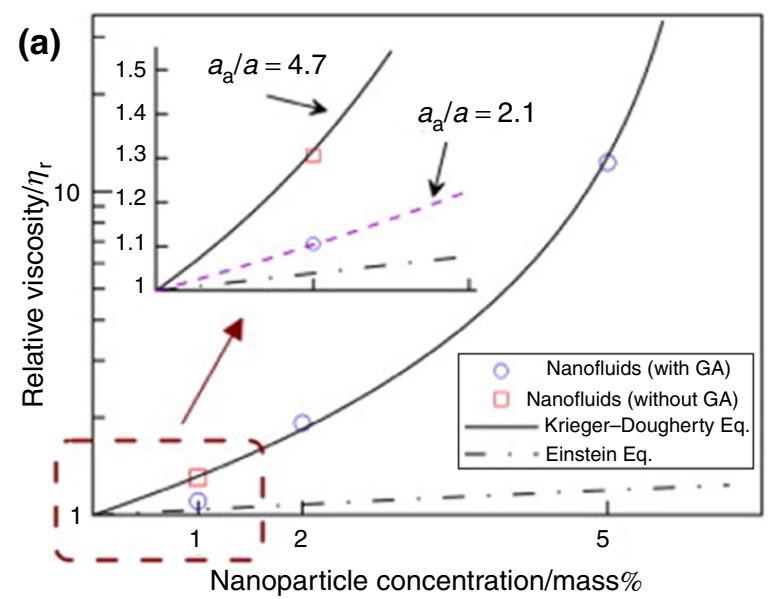

Fig. 3 Comparison of the relative viscosity between the experimental data and Krieger-Dougherty model. a Viscosity of MWCNT-based molten salt nanofluids at $550{ }^{\circ} \mathrm{C}$. b Viscosity of $\mathrm{Al}_{2} \mathrm{O}_{3}$-based ionic

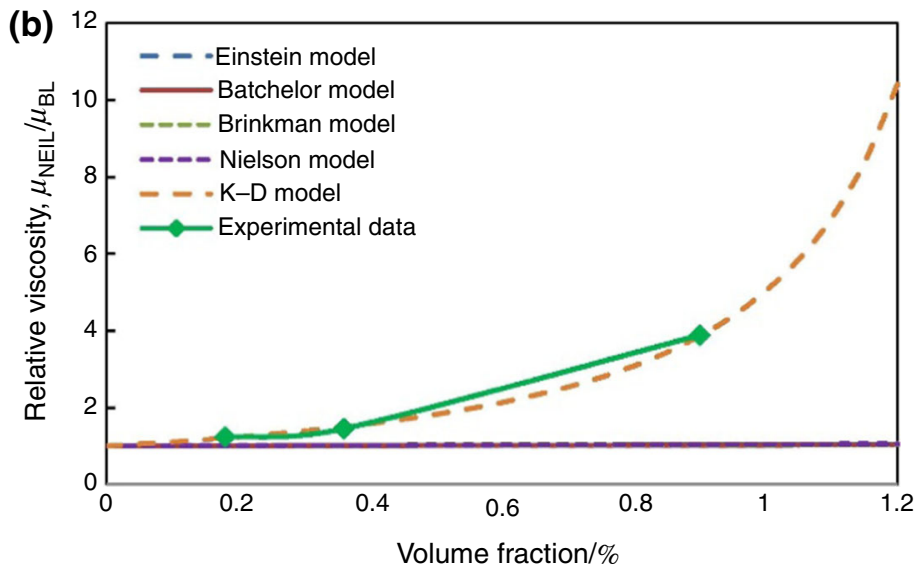

liquid nanofluids at $30^{\circ} \mathrm{C}$. Reprinted from [90] and [94] with the permissions from Elsevier

Table 5 Specific heat of $\mathrm{NaNO}_{3}-\mathrm{KNO}_{3}$ binary salt mixture (60-40 mass\%) and the nanofluids obtained with 1.0 mass $\%$ of different nanoparticles $\left(\mathrm{SiO}_{2}, \mathrm{Al}_{2} \mathrm{O}_{3}\right.$ and $\left.\mathrm{SiO}_{2} / \mathrm{Al}_{2} \mathrm{O}_{3}\right)$ [68]

\begin{tabular}{|c|c|c|c|c|c|c|}
\hline Material & $\begin{array}{l}\text { Screw } \\
\text { speed/rpm }\end{array}$ & $\begin{array}{l}\text { Mixing } \\
\text { time/min }\end{array}$ & $\begin{array}{l}\text { Specific heat (solid } \\
\text { phase)/ } \mathrm{KJ} \mathrm{kg}^{-1} \mathrm{~K}^{-1}\end{array}$ & $\begin{array}{l}\text { Enhancement } \\
\text { (solid phase)/\% }\end{array}$ & $\begin{array}{l}\text { Specific heat (liquid } \\
\text { phase). } \mathrm{KJ} \mathrm{kg}^{-1} \mathrm{~K}^{-1}\end{array}$ & $\begin{array}{l}\text { Enhancement } \\
\text { (liquid phase)/\% }\end{array}$ \\
\hline Base salt & & & $1.589(0.065)$ & - & $1.632(0.048)$ & - \\
\hline \multirow{5}{*}{$\begin{array}{l}\text { Base } \\
\text { salt }+\mathrm{SiO}_{2}\end{array}$} & \multirow[t]{2}{*}{100} & 15 & $2.003(0.022)$ & 26.1 & $1.672(0.022)$ & 2.5 \\
\hline & & 30 & $1.349(0.043)$ & -15.1 & $1.173(0.067)$ & -28.1 \\
\hline & \multirow[t]{2}{*}{200} & 15 & $2.000(0.011)$ & 25.9 & $1.675(0.024)$ & 2.6 \\
\hline & & 30 & $2.049(0.018)$ & 28.9 & $1.599(0.046)$ & -2.0 \\
\hline & Model & & 1.582 & -0.4 & 1.623 & -0.6 \\
\hline \multirow{5}{*}{$\begin{array}{l}\text { Base } \\
\text { salt }+\mathrm{Al}_{2} \mathrm{O}_{3}\end{array}$} & \multirow[t]{2}{*}{100} & 15 & $1.989(0.045)$ & 25.2 & $1.677(0.076)$ & 2.8 \\
\hline & & 30 & $1.754(0.055)$ & 10.4 & $1.505(0.044)$ & -7.8 \\
\hline & \multirow[t]{2}{*}{200} & 15 & $1.880(0.045)$ & 18.3 & $1.662(0.041)$ & 1.8 \\
\hline & & 30 & $1.939(0.009)$ & 22.0 & $1.618(0.025)$ & -0.9 \\
\hline & Model & & 1.585 & -0.3 & 1.627 & -0.3 \\
\hline \multirow{5}{*}{$\begin{array}{l}\text { Base } \\
\text { salt }+\mathrm{SiO}_{2} / \\
\mathrm{Al}_{2} \mathrm{O}_{3}\end{array}$} & \multirow[t]{2}{*}{100} & 15 & $2.043(0.005)$ & 28.6 & $1.692(0.022)$ & 3.7 \\
\hline & & 30 & $2.045(0.057)$ & 28.7 & $1.888(0.003)$ & 15.7 \\
\hline & \multirow[t]{2}{*}{200} & 15 & $2.053(0.048)$ & 29.2 & $1.691(0.036)$ & 3.6 \\
\hline & & 30 & $2.417(0.015)$ & 52.1 & $1.936(0.007)$ & 18.6 \\
\hline & Model & & 1.582 & -0.4 & 1.624 & -0.5 \\
\hline
\end{tabular}

$$
\begin{aligned}
& {\left[\mathrm{C}_{4} \operatorname{mim}\right]\left[\mathrm{CF}_{3} \mathrm{SO}_{3}\right]>\left[\mathrm{C}_{4} \mathrm{mpyrr}\right]\left[\left(\mathrm{CF}_{3} \mathrm{SO}_{2}\right)_{2} \mathrm{~N}\right]} \\
& \quad>\left[\mathrm{C}_{6} \operatorname{mim}\right]\left[\mathrm{BF}_{4}\right]>\left[\mathrm{C}_{4} \operatorname{mim}\right]\left[\mathrm{PF}_{6}\right]>\left[\mathrm{C}_{6} \operatorname{mim}\right]\left[\mathrm{PF}_{6}\right] .
\end{aligned}
$$

Fox et al. [95] realized that the enhancement ratio of $\lambda$ increases significantly with the increase in temperature, which is quite different from the results by Paul et al. [94]. They found that the whisker-shaped $\mathrm{NP}\left(\mathrm{Al}_{2} \mathrm{O}_{3}\right)$ is more beneficial than the sphere shape.

The thermal conductivity enhancement of [HMIM][BF4]-based NFs, as shown in Fig. 4, can reach up to $26 \%$. Wang et al. [32] and Liu et al. [33] measured the same ILBNFs ([HMIM][BF4] + GE) with 0.03 mass\% and 0.06 mass $\%$ fractions, and the results are very similar. Only Liu et al. [33] tested data above $80{ }^{\circ} \mathrm{C}$, and they found that the $\lambda$ enhancement of the high concentration $(0.06$ mass $\%)$ increases with the increase in temperature, while for the low concentrations (0.01 mass\% and 0.03 mass \%) the enhancements are almost independent on temperature. The results by Chen et al. [96] also showed that the enhancement at 0.01 mass\% is steady, and the 
Table 6 Summary of experimental works on ILBNFs

\begin{tabular}{|c|c|c|c|c|c|}
\hline References & Ionic liquid & Nanoparticles & $\begin{array}{l}\text { Size and } \\
\text { concentration }\end{array}$ & Properties & Temperature \\
\hline $\begin{array}{l}\text { Nieto de } \\
\text { Castro et al. [93] }\end{array}$ & $\begin{array}{l}{\left[\mathrm{C}_{6} \mathrm{mim}\right]\left[\mathrm{BF}_{4}\right]} \\
{\left[\mathrm{C}_{4} \mathrm{mim}\right]\left[\mathrm{CF}_{3} \mathrm{SO}_{3}\right]} \\
{\left[\mathrm{C}_{4} \mathrm{mpyrr}\right]\left[\left(\mathrm{CF}_{3} \mathrm{SO}_{2}\right)_{2} \mathrm{~N}\right]} \\
{\left[\mathrm{C}_{4} \mathrm{mim}\right]\left[\mathrm{PF}_{6}\right]} \\
{\left[\mathrm{C}_{6} \mathrm{mim}\right]\left[\mathrm{PF}_{6}\right]}\end{array}$ & MWCNT & $1.0,1.5$ mass $\%$ & $\lambda, C_{\mathrm{p}}$ & $20-80{ }^{\circ} \mathrm{C}$ \\
\hline Bridges et al. [99] & {$\left[\mathrm{C}_{4} \mathrm{mmim}\right]\left[\mathrm{NTf}_{2}\right]$} & $\begin{array}{l}\mathrm{Al}_{2} \mathrm{O}_{3} \\
\text { Carbon Black (CB) }\end{array}$ & $\begin{array}{l}0.5,1.0, \\
2.5 \text { mass } \%\end{array}$ & $C_{\mathrm{p}}, \mu$ & $\begin{array}{l}60-360{ }^{\circ} \mathrm{C} \\
\quad\left(\text { for } C_{\mathrm{p}}\right) \\
25^{\circ} \mathrm{C}(\text { for } \mu)\end{array}$ \\
\hline Wang et al. [98] & {$[\mathrm{Bmim}]\left[\mathrm{PF}_{6}\right]$} & $\mathrm{Au}$ & $\begin{array}{l}5.2,18.4,29.9 \\
59.4 \mathrm{~nm} \\
0.00102 \mathrm{vol} \%\end{array}$ & $\lambda$ & $33-81{ }^{\circ} \mathrm{C}$ \\
\hline Fox et al. [95] & {$\left[\mathrm{C}_{4} \mathrm{mmim}\right]\left[\mathrm{NTf}_{2}\right]$} & $\begin{array}{l}\mathrm{Al}_{2} \mathrm{O}_{3 \text { (spheres) }}, \mathrm{Al}_{2} \mathrm{O}_{3 \text { (whiskers) }} \\
\mathrm{SiO} 2, \mathrm{CuO}, \mathrm{ZnO}, \mathrm{Fe} 2 \mathrm{O} 3, \mathrm{Au}, \mathrm{SGNF}, \\
\text { MWCNT, SWCNT, CB }\end{array}$ & $\begin{array}{l}0.5,2.5 \text { mass } \% \\
2-100 \mathrm{~nm}\end{array}$ & $\lambda, \mu$ & $\begin{array}{l}25-60{ }^{\circ} \mathrm{C} \text { (for } \\
\lambda \text { ) } \\
20-300{ }^{\circ} \mathrm{C} \\
(\text { for } \mu \text { ) }\end{array}$ \\
\hline Wang et al. [32] & {$[\mathrm{Hmim}]\left[\mathrm{BF}_{4}\right]$} & GE, MWCNT & $0.03,0.06$ mass $\%$ & $\lambda, C_{\mathrm{p}}$ & $25-65^{\circ} \mathrm{C}$ \\
\hline Liu et al. [33] & {$[\mathrm{Hmim}]\left[\mathrm{BF}_{4}\right]$} & GE & $\begin{array}{l}0.01,0.03, \\
0.06 \text { mass } \%\end{array}$ & $\lambda, C_{\mathrm{p}}, \mu$ & $25-200$ \\
\hline Franca et al. [97] & $\begin{array}{l}{\left[\mathrm{C}_{4} \mathrm{C}_{1} \mathrm{im}\right]\left[\mathrm{C}(\mathrm{CN})_{3}\right]} \\
{\left[\mathrm{C}_{4} \mathrm{C}_{1} \mathrm{im}\right]\left[\mathrm{C}(\mathrm{CN})_{2}\right]} \\
{\left[\mathrm{C}_{4} \mathrm{C}_{1} \mathrm{im}\right][\mathrm{SCN}]} \\
{\left[\mathrm{C}_{4} \mathrm{C}_{1} \mathrm{im}\right]\left[\mathrm{NTf}_{2}\right]}\end{array}$ & SWCNT, GE & $\begin{array}{l}0.95-8.17 \mathrm{~nm} \\
0.5,1.0 \text { mass } \%\end{array}$ & $\lambda$ & $90-150{ }^{\circ} \mathrm{C}$ \\
\hline Paul et al. [94] & $\begin{array}{l}{\left[\mathrm{C}_{4} \mathrm{mim}\right]\left[\mathrm{NTf}_{2}\right]} \\
{\left[\mathrm{C}_{4} \mathrm{mmim}\right]\left[\mathrm{NTf}_{2}\right]} \\
{\left[\mathrm{C}_{4} \mathrm{mpyrr}\right]\left[\mathrm{NTf}_{2}\right]} \\
{\left[\mathrm{C}_{4111}\right]\left[\mathrm{NTf}_{2}\right]}\end{array}$ & $\mathrm{Al}_{2} \mathrm{O}_{3}$ & $\begin{array}{l}0.5,1.0, \\
2.5 \text { mass } \%\end{array}$ & $\lambda, C_{\mathrm{p}}, \mu$ & $\begin{array}{l}10-70{ }^{\circ} \mathrm{C} \text { (for } \\
\lambda \text { ) } \\
25-345^{\circ} \mathrm{C} \\
\quad \text { (for } C_{\mathrm{p}} \text { ) } \\
20-90{ }^{\circ} \mathrm{C} \text { (for } \\
\mu \text { ) }\end{array}$ \\
\hline Chen et al. [96] & {$[\mathrm{Hmim}]\left[\mathrm{BF}_{4}\right]$} & $\mathrm{SiC}$ & $\begin{array}{l}0.01,0.03, \\
0.06 \text { mass } \% \\
30 \mathrm{~nm}\end{array}$ & $\lambda, C_{\mathrm{p}}, \mu$ & $0-80^{\circ} \mathrm{C}$ \\
\hline
\end{tabular}

increase trend of $\mathrm{SiC}$ with 0.03 mass $\%$ is quite similar to the data of 0.03 mass\% MWCNT by Wang et al. [32]. By comparing between the experimental data from these three works, it reveals that the effective order is: $\mathrm{GE}>$ MWCNT $>$ SiC. Another noteworthy thing is that these three works with very low NPs mass fractions can reach the same level of enhancement of $\lambda$, as shown in Fig. 5, and even higher than them. This is hard to explain.

All the above-mentioned works have confirmed that the addition of NPs in the ionic liquid can improve $\lambda$. However, an experimental work by Fox et al. [95], with 11 kinds of NPs dispersed into $\left[\mathrm{C}_{4} \mathrm{mmim}\right]\left[\mathrm{Tf}_{2}\right]$, with 0.5 mass \% concentration, shows that only three nanomaterials increase $\lambda$ of the base fluid: $\mathrm{Al}_{2} \mathrm{O}_{3}$ (spheres), $\mathrm{Al}_{2} \mathrm{O}_{3}$ (whiskers) and MWCNT, while others are all below the neat IL, as shown in Fig. 6. This conclusion contradicts the findings of many other scholars. Franca et al. [97] dispersed single-wall carbon nanotube (SWCNT) and GE into four kinds of ionic liquids, corresponding to the $14.55-34.31 \%$ and $8.21-36.22 \%$ enhancement of $\lambda$, respectively. For addition of SWCNTs into the four ILs, the effective order is $\left[\mathrm{C}_{4} \mathrm{C}_{1} \mathrm{im}\right]\left[\mathrm{NTf}_{2}\right]>\left[\mathrm{C}_{4} \mathrm{C}_{1}\right.$ $\mathrm{im}]\left[\mathrm{C}(\mathrm{CN})_{2}\right]>\left[\mathrm{C}_{4} \mathrm{C}_{1} \mathrm{im}\right][\mathrm{SCN}]>\left[\mathrm{C}_{4} \mathrm{C}_{1} \mathrm{im}\right]\left[\mathrm{C}(\mathrm{CN})_{3}\right]$; however, by adding $\mathrm{GE}$ into the four ILs, the effective order is $\left[\mathrm{C}_{4} \mathrm{C}_{1} \mathrm{im}\right]\left[\mathrm{C}(\mathrm{CN})_{2}\right]>\left[\mathrm{C}_{4} \mathrm{C}_{1} \mathrm{im}\right][\mathrm{SCN}]>\left[\mathrm{C}_{4} \mathrm{C}_{1}\right.$ $\mathrm{im}]\left[\mathrm{NTf}_{2}\right]>\left[\mathrm{C}_{4} \mathrm{C}_{1} \mathrm{im}\right]\left[\mathrm{C}(\mathrm{CN})_{3}\right]$. The different orders are due to the different interactions between SWCNT and GE to the organic liquids. The effect of NP size was studied by Wang et al. [98], with the same concentration of $\mathrm{Au}$ (5.2, 18.4, 29.9 and $59.4 \mathrm{~nm}$ ) dispersed into $\left[\mathrm{Bmim}^{2}\left[\mathrm{PF}_{6}\right]\right.$. The results show that the enhancement of $\lambda$ increases with the increase in temperature and more significantly at high 


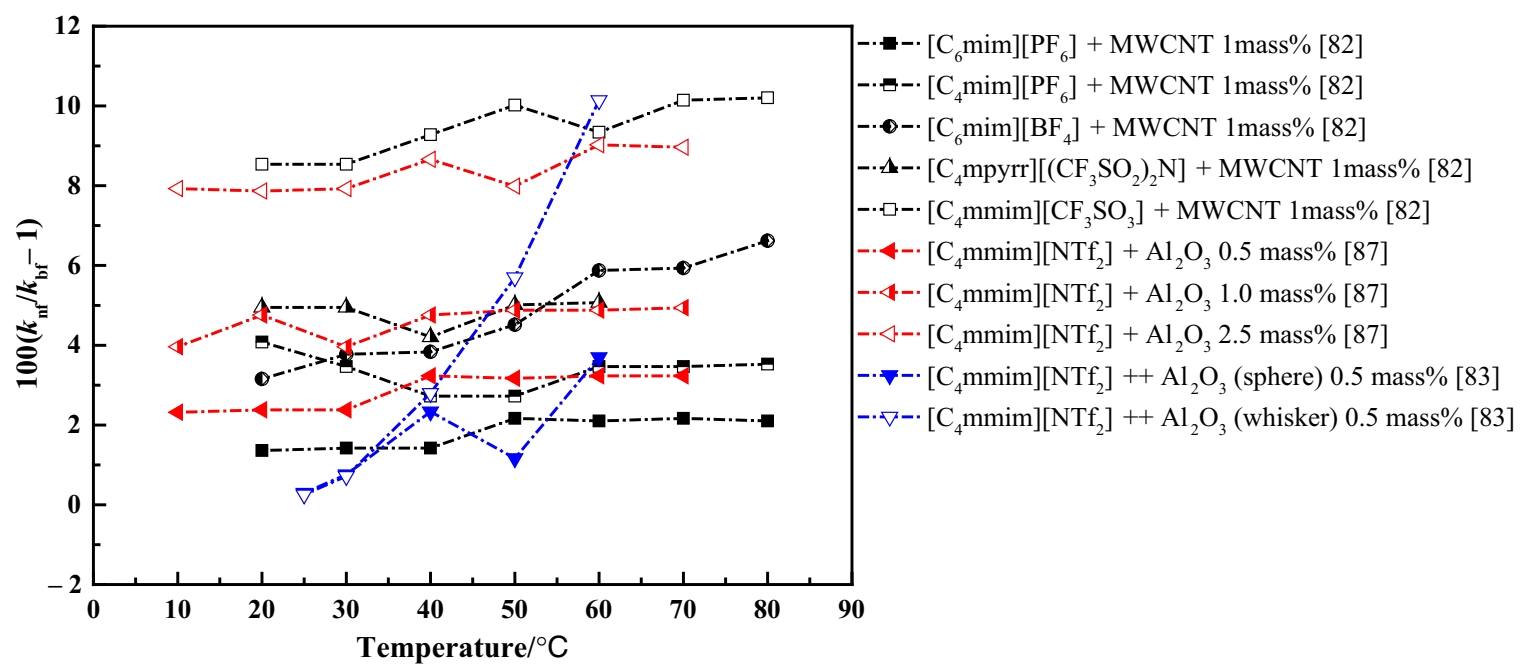

Fig. 4 Thermal conductivity enhancement of ILBNFs, under $80^{\circ} \mathrm{C}$

Fig. 5 Thermal conductivity enhancement of [HMIM][BF4]based nanofluids

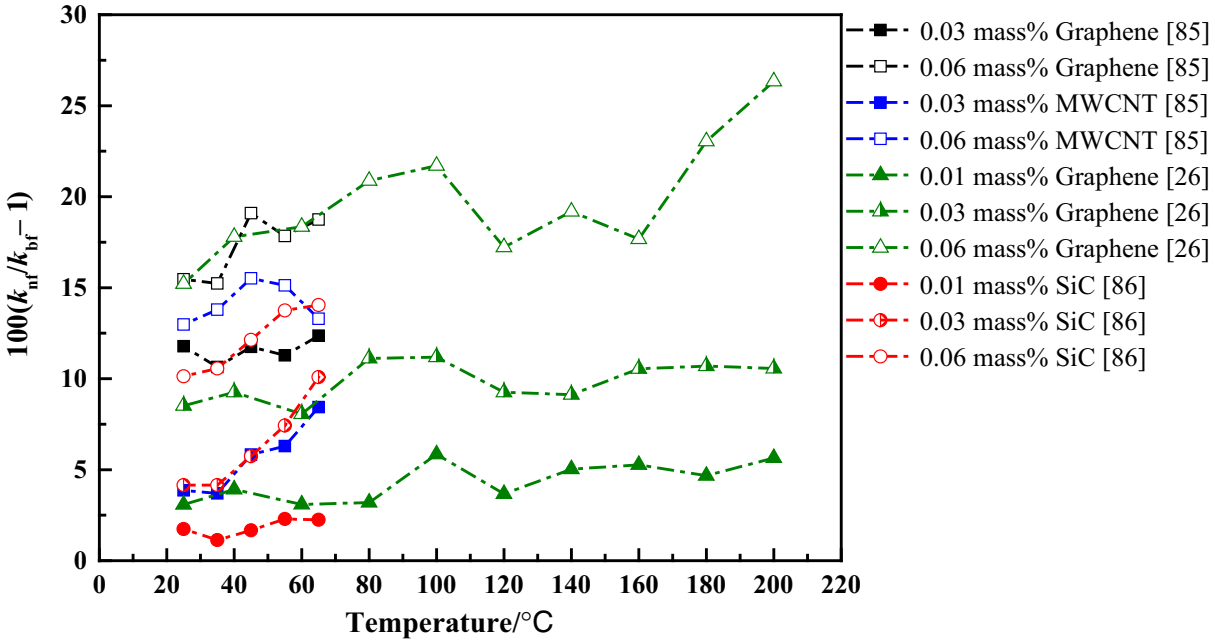

shown in Fig. 7. This may explain the abnormal results by Fox et al. [95].

The $C_{\mathrm{p}}$ of ILBNFs presents interesting results according to the published works. Nieto de Castro et al. [93] found that $C_{\mathrm{p}}$ of $\left[\mathrm{C}_{4} \mathrm{mim}\right]\left[\mathrm{PF}_{6}\right]+\mathrm{MWCNT}$ presents an unexpected jump within the temperature range from 350 to $400 \mathrm{~K}$, as shown in Fig. 8. Liu et al. [33] found the "jump phenomenon," not only for the ILBNFs ([Hmim] $\left[\mathrm{BF}_{4}\right]-$ $+\mathrm{GE}$ ) but also for the base ionic liquid ([Hmim] $\left.\left[\mathrm{BF}_{4}\right]\right)$, as shown in Fig. 9, and they did not give any explanation for it. Other researchers did not report the same abnormal phenomenon. Besides, Wang et al. [32] and Liu et al. [33] reported that the $C_{\mathrm{p}}$ values of $[\mathrm{Hmim}]\left[\mathrm{BF}_{4}\right]+\mathrm{GE} /$ MWCNT and $[\mathrm{Hmim}]\left[\mathrm{BF}_{4}\right]+\mathrm{GE}$ are lower than those of the base fluids and decrease with the increase in concentrations of NPs. There are some contradictory conclusions by Paul et al. [94] $\left(\left[\mathrm{C}_{4} \mathrm{mmim}\right]\left[\mathrm{NTf}_{2}\right]+\mathrm{Al}_{2} \mathrm{O}_{3}\right)$ and by Chen et al. [96] ([Hmim] $\left.\left[\mathrm{BF}_{4}\right]+\mathrm{SiC}\right)$. Bridges et al. [99]
Fig. 6 Thermal conductivity of ILBNFs for various NPs with $\left[\mathrm{C}_{4} \mathrm{mmim}\right]\left[\mathrm{Tf}_{2}\right]$ base fluid at 0.5 mass $\%$ and $50{ }^{\circ} \mathrm{C}$. Reprinted from [83] with the permission from ACS Publications

temperature. Besides, the enhancement reaches a peak value at a particle size of $18.4 \mathrm{~nm}$, and the enhancement decreases obviously for the particle size above $18.4 \mathrm{~nm}$, as 


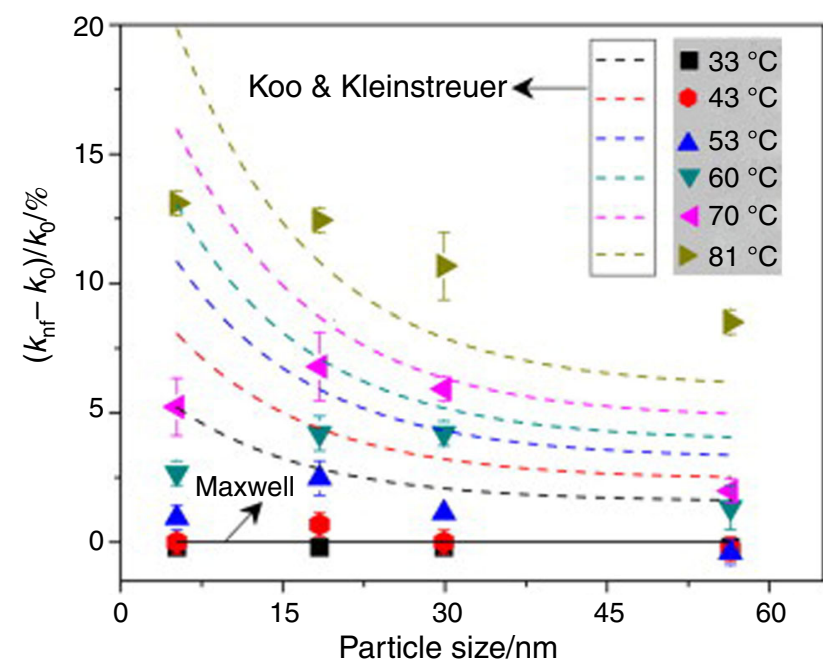

Fig. 7 Thermal conductivity for different particle sizes under various temperatures for gold ILBNFs, with the same volume fraction of $0.00102 \%$, and comparison with the Maxwell model. Reprinted from [87] with the permission from Elsevier

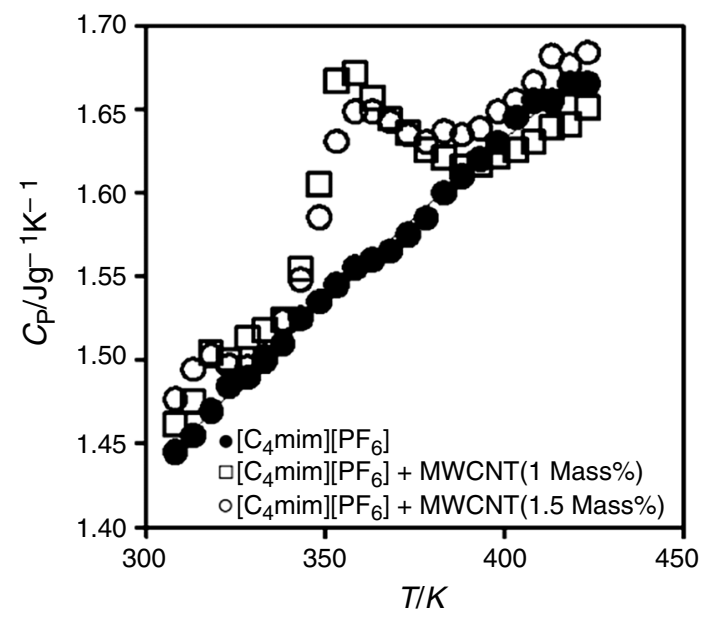

Fig. 8 Specific heat of $\left[\mathrm{C}_{4} \mathrm{mim}\right]\left[\mathrm{PF}_{6}\right]$-based NFs for two different MWCNT mass fractions of 0.01 and 0.015 as a function of temperature. Reprinted from [81] with the permission from ACS Publications

reported that the $\mathrm{Al}_{2} \mathrm{O}_{3} \mathrm{NPs}$ addition into $\left[\mathrm{C}_{4} \mathrm{mmim}\right]\left[\mathrm{NTf}_{2}\right]$ can cause a $40 \%$ increase in $C_{\mathrm{p}}$, but a decrease of about $30 \%$ was observed for CB (carbon black) NP. The decrease in $C_{\mathrm{p}}$ for the CB NFs might be due to the increase in $\lambda$ in the system, because carbonaceous materials are known to have higher $\lambda$.

The published works have confirmed that ILBNFs are also non-Newtonian fluids, and $\mu$ decreases sharply with the increase in temperature. Most experimental data indicate that $\mu$ increases with the increase in NP concentration, but only Liu et al. [33] found that the $\mu$ is slightly decreased when adding the NPs. Paul et al. [94] found that

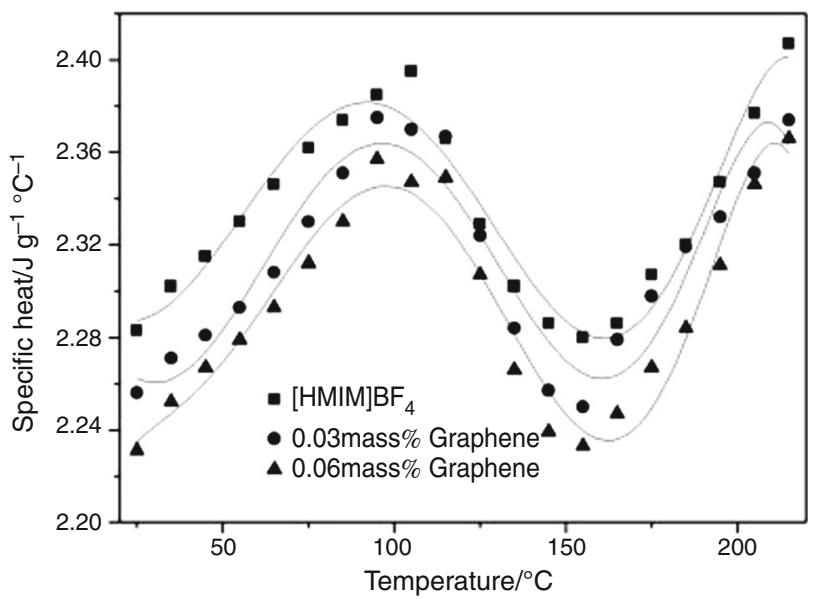

Fig. 9 Specific heat of $[\mathrm{HMIM}]\left[\mathrm{BF}_{4}\right]$-based NFs as a function of temperature. Reprinted from [25] with the permission from Elsevier

the Krieger-Dougherty model can also fit well with the experimental data of $\mu$, as shown in Fig. 3b.

The forced convection heat transfer of ILBNFs under laminar and turbulent flow regimes was experimentally studied by Paul [40], with different volume concentrations ( $0.18 \mathrm{vol} \%, 0.36 \mathrm{vol} \%$ and $0.9 \mathrm{vol} \%)$ of $\mathrm{Al}_{2} \mathrm{O}_{3}$ NPs dispersed into $\left[\mathrm{C}_{4} \mathrm{mim}\right]\left[\mathrm{NTf}_{2}\right]$. The convective heat transfer performance of ILBNFs increases with the nanoparticle concentration, and the enhancement of heat transfer coefficient can be up to $27 \%$ and $40 \%$ for laminar flow and turbulent flow, respectively. Minea and EI-Maghlany [100] also added the $\mathrm{Al}_{2} \mathrm{O}_{3}$ NPs $(0.5$ mass $\%, 1.0$ mass $\%$ and 2.5 mass $\%$ ) into $\left[\mathrm{C}_{4} \mathrm{mim}\right]\left[\mathrm{NTf}_{2}\right]$ and compared with the regular $\mathrm{NF}\left(\mathrm{Al}_{2} \mathrm{O}_{3}\right.$-water $)$. The heat transfer performances of 0.5 mass \% and 1.0 mass \% MSBNFs are superior to the water-based $\mathrm{NF}$, but the heat transfer performance of the 2.5 mass\% NF is lower than the regular BF.

For future work, due to the wide variety of molten salts and ionic liquids, more systematic experimental investigations are needed. The synthesis method has a great influence on stability and measured values, so it is very worthwhile for further study. It is better to form a nanofluid synthetic protocol. In addition, more experimental data of ILBNFs at high temperatures are required. The prediction of $\mu$ needs further verification.

\section{Conclusions}

This paper reviews thermal properties of molten-salt-based nanofluid (MSBNF) and ionic-liquid-based nanofluid (ILBNF), which can be used for medium-to-high temperature applications. The difference in preparation and stabilization techniques between the two NFs and traditional NFs is also discussed. 
For the MSBNF: (1) Most studies focused on its enhancement of $C_{\mathrm{p}}$, as high-temperature thermal storage fluid or medium-temperature phase-change thermal storage fluid, due to the high boiling point. (2) For a comprehensive comparison, the effective order of specific heat enhancement for $\mathrm{NPs}$ is $\mathrm{SiO}_{2}-\mathrm{Al}_{2} \mathrm{O}_{3}>\mathrm{Al}_{2} \mathrm{O}_{3}>\mathrm{SiO}_{2}$ $>\mathrm{GE}>\mathrm{MgO}>\mathrm{TiO}_{2}$. (3) There are two most commonly used base molten salts. The growth rate of specific heat for $62 \% \mathrm{Li}_{2} \mathrm{CO}_{3}+38 \% \mathrm{~K}_{2} \mathrm{CO}_{3}$ is independent of the temperature variation, while $60 \% \mathrm{NaNO}_{3}+40 \% \mathrm{KNO}_{3}$ is very volatile with the temperature. (4) The $\lambda$ also has a significant enhancement based on the limited experimental data, and the maximum enhancement can reach up to $47 \%$.

For the ILBNF: (1) It is suitable as a heat transfer fluid, due to the low melting point. (2) The [HMIM][BF4] seems to be an effective base ionic liquid for which an addition of a very small amount of NPs (GE 0.06 mass\%) can reach up to a high increase (15-26\%) in thermal conductivity, within a temperature range from 25 to $200{ }^{\circ} \mathrm{C}$. (3) An effective order of $\lambda$ enhancement for NPs is GE $>$ MWCNT $>\mathrm{SiC}$ based on the [HMIM][BF4] fluid. (4) The $C_{\mathrm{p}}$ of ILBNF can either increase or decrease by matching different nanomaterials and base fluids. A jump phenomenon in $C_{\mathrm{p}}$ was also observed by a few researchers, but there is no explanation for it.

For the theoretical models: (1) The $C_{\mathrm{p}}$ and $\lambda$ for the two kinds of NFs are not be well predicted by traditional theoretical or empirical models. (2) The $\mu$ for both NFs can be well predicted by the Krieger-Dougherty model.

Acknowledgements This study was supported by the China Scholarship Council (201706120182), the Swedish Research Council (VR) and the Natural Science Foundation of China (Grant No. 51476042).

Open Access This article is distributed under the terms of the Creative Commons Attribution 4.0 International License (http://creative commons.org/licenses/by/4.0/), which permits unrestricted use, distribution, and reproduction in any medium, provided you give appropriate credit to the original author(s) and the source, provide a link to the Creative Commons license, and indicate if changes were made.

\section{References}

1. Choi SU, Eastman JA. Enhancing thermal conductivity of fluids with nanoparticles. Argonne: Argonne National Lab; 1995.

2. Das SK, Choi SUS, Patel HE. Heat transfer in nanofluids-a review. Heat TransfEng. 2006;27:3-19.

3. Rashidi S, Mahian O, Languri EM. Applications of nanofluids in condensing and evaporating systems. J Therm Anal Calorim. 2018;131:2027-39.

4. Leena M, Srinivasan S. A comparative study on thermal conductivity of $\mathrm{TiO}_{2} /$ ethylene glycol-water and $\mathrm{TiO}_{2} /$ propylene glycol-water nanofluids. J Therm Anal Calorim. 2018;131:1987-98.

5. Zadeh AD, Toghraie D. Experimental investigation for developing a new model for the dynamic viscosity of silver/ethylene glycol nanofluid at different temperatures and solid volume fractions. J Therm Anal Calorim. 2018;131:1449-61.

6. E. Bellos, C. Tzivanidis, A review of concentrating solar thermal collectors with and without nanofluids. J Therm Anal Calorim. 2018;1-24.

7. S. Rashidi, N. Karimi, O. Mahian, J.A. Esfahani, A concise review on the role of nanoparticles upon the productivity of solar desalination systems. J Therm Anal Calorim. 2018;1-15.

8. H. Masuda, A. Ebata, K. Teramae, Alteration of thermal conductivity and viscosity of liquid by dispersing ultra-fine particles, dispersion of $\mathrm{Al}_{2} \mathrm{O}_{3}, \mathrm{SiO}_{2}$ and $\mathrm{TiO}_{2}$ ultra-fine particles. Netsu Bussei. 1993;7:227-33.

9. J. Eastman, U. Choi, S. Li, L. Thompson, S. Lee, Enhanced thermal conductivity through the development of nanofluids. MRS Online Proceedings Library Archive, 457 (1996).

10. Eastman JA, Choi S, Li S, Yu W, Thompson L. Anomalously increased effective thermal conductivities of ethylene glycolbased nanofluids containing copper nanoparticles. Appl Phys Lett. 2001;78:718-20.

11. Moghadassi A, Hosseini SM, Henneke DE. Effect of $\mathrm{CuO}$ nanoparticles in enhancing the thermal conductivities of monoethylene glycol and paraffin fluids. Ind Eng Chem Res. 2010;49:1900-4.

12. Murshed S, Leong K, Yang C. A combined model for the effective thermal conductivity of nanofluids. Appl Therm Eng. 2009;29:2477-83.

13. Buongiorno J, Venerus DC, Prabhat N, McKrell T, Townsend J, Christianson R, Tolmachev YV, Keblinski P, Hu L-W, Alvarado JL, Bang IC, Bishnoi SW, Bonetti M, Botz F, Cecere A, Chang Y, Chen G, Chen H, Chung SJ, Chyu MK, Das SK, Di Paola R, Ding Y, Dubois F, Dzido G, Eapen J, Escher W, Funfschilling D, Galand Q, Gao J, Gharagozloo PE, Goodson KE, Gutierrez JG, Hong H, Horton M, Hwang KS, Iorio CS, Jang SP, Jarzebski AB, Jiang Y, Jin L, Kabelac S, Kamath A, Kedzierski MA, Kieng LG, Kim C, Kim J-H, Kim S, Lee SH, Leong KC, Manna I, Michel B, Ni R, Patel HE, Philip J, Poulikakos D, Reynaud C, Savino R, Singh PK, Song P, Sundararajan T, Timofeeva E, Tritcak T, Turanov AN, Van Vaerenbergh S, Wen D, Witharana S, Yang C, Yeh W-H, Zhao X-Z, Zhou S-Q. A benchmark study on the thermal conductivity of nanofluids. J Appl Phys. 2009;106:094312.

14. Sundar LS, Sharma KV, Singh MK, Sousa ACM. Hybrid nanofluids preparation, thermal properties, heat transfer and friction factor-a review. Renew Sustain Energy Rev. 2017;68:185-98.

15. Das PK. A review based on the effect and mechanism of thermal conductivity of normal nanofluids and hybrid nanofluids. J Mol Liq. 2017;240:420-46.

16. Hemmat Esfe M, Saedodin S, Yan W-M, Afrand M, Sina N. Study on thermal conductivity of water-based nanofluids with hybrid suspensions of $\mathrm{CNTs} / \mathrm{Al}_{2} \mathrm{O}_{3}$ nanoparticles. J Therm Anal Calorim. 2016;124:455-60.

17. M. Parlak, Ö. Östürk, Ü.N. Temel, K. Yapici, Heat transfer performance of water based nanofluids containing various types of metal oxide nanoparticles in an air-cooled microchannel heat exchanger. In 2017 16th IEEE Intersociety conference on thermal and thermomechanical phenomena in electronic systems (ITherm); 2017. p. 1-5.

18. Hemmat Esfe M, Saedodin S, Mahian O, Wongwises S. Thermal conductivity of $\mathrm{Al}_{2} \mathrm{O}_{3}$ /water nanofluids. J Therm Anal Calorim. 2014;117:675-81.

19. Mutuku WN. Ethylene glycol (EG)-based nanofluids as a coolant for automotive radiator. Asia Pac J Comput Eng. 2016;3:1.

20. Hemmat Esfe M, Karimipour A, Yan W-M, Akbari M, Safaei MR, Dahari M. Experimental study on thermal conductivity of 
ethylene glycol based nanofluids containing $\mathrm{Al}_{2} \mathrm{O}_{3}$ nanoparticles. Int J Heat Mass Transf. 2015;88:728-34.

21. Hemmat Esfe M, Saedodin S, Asadi A, Karimipour A. Thermal conductivity and viscosity of $\mathrm{Mg}(\mathrm{OH})_{2}$-ethylene glycol nanofluids. J Therm Anal Calorim. 2015;120:1145-9.

22. Botha SS, Ndungu P, Bladergroen BJ. Physicochemical properties of oil-based nanofluids containing hybrid structures of silver nanoparticles supported on silica. Ind Eng Chem Res. 2011;50:3071-7.

23. Liu H, Bai M, Qu Y. The impact of oil-based diamond nanofluids on diesel engine performance. Berlin: Springer; 2013. p. 1313-9.

24. Beheshti A, Shanbedi M, Heris SZ. Heat transfer and rheological properties of transformer oil-oxidized MWCNT nanofluid. J Therm Anal Calorim. 2014;118:1451-60.

25. Ghadimi A, Saidur R, Metselaar H. A review of nanofluid stability properties and characterization in stationary conditions. Int J Heat Mass Transf. 2011;54:4051-68.

26. Zeng Y-X, Zhong X-W, Liu Z-Q, Chen S, Li N. Preparation and enhancement of thermal conductivity of heat transfer oil-based $\mathrm{MoS}_{2}$ nanofluids. J Nanomater. 2013;2013:3.

27. Tian Y, Zhao CY. A review of solar collectors and thermal energy storage in solar thermal applications. Appl Energy. 2013;104:538-53.

28. Zhang Z, Yuan Y, Ouyang L, Sun Q, Cao X, Alelyani S. Enhanced thermal properties of $\mathrm{Li}_{2} \mathrm{CO}_{3}-\mathrm{Na}_{2} \mathrm{CO}_{3}-\mathrm{K}_{2} \mathrm{CO}_{3}$ nanofluids with nanoalumina for heat transfer in high-temperature CSP systems. J Therm Anal Calorim. 2017;128:1783-92.

29. Shin D, Banerjee D. Enhancement of specific heat capacity of high-temperature silica-nanofluids synthesized in alkali chloride salt eutectics for solar thermal-energy storage applications. Int $\mathbf{J}$ Heat Mass Transf. 2011;54:1064-70.

30. Valderrama JO, Campusano RA. Melting properties of molten salts and ionic liquids. Chemical homology, correlation, and prediction. C R Chim. 2016;19:654-64.

31. Nieto de Castro C, Lourenço M, Ribeiro A, Langa E, Vieira S, Goodrich P, Hardacre C. Thermal properties of ionic liquids and ionanofluids of imidazolium and pyrrolidinium liquids. J Chem Eng Data. 2009;55:653-61.

32. Wang F, Han L, Zhang Z, Fang X, Shi J, Ma W. Surfactant-free ionic liquid-based nanofluids with remarkable thermal conductivity enhancement at very low loading of graphene. Nanoscale Res Lett. 2012;7:314.

33. Liu J, Wang F, Zhang L, Fang X, Zhang Z. Thermodynamic properties and thermal stability of ionic liquid-based nanofluids containing graphene as advanced heat transfer fluids for medium-to-high-temperature applications. Renew Energy. 2014;63:519-23.

34. $\mathrm{Yu} \mathrm{W}$, Xie $\mathrm{H}$. A review on nanofluids: preparation, stability mechanisms, and applications. J Nanomater. 2012;2012:1-17.

35. Wang JJ, Zheng RT, Gao JW, Chen G. Heat conduction mechanisms in nanofluids and suspensions. Nano Today. 2012;7:124-36.

36. Muñoz-Sánchez B, Nieto-Maestre J, Iparraguirre-Torres I, García-Romero A, Sala-Lizarraga JM. Molten salt-based nanofluids as efficient heat transfer and storage materials at high temperatures. An overview of the literature. Renew Sustain Energy Rev. 2018;82:3924-45.

37. Akoh H, Tsukasaki Y, Yatsuya S, Tasaki A. Magnetic properties of ferromagnetic ultrafine particles prepared by vacuum evaporation on running oil substrate. J Cryst Growth. 1978;45:495-500.

38. Zhang HL, Baeyens J, Degrève J, Cacères G. Concentrated solar power plants: review and design methodology. Renew Sustain Energy Rev. 2013;22:466-81.
39. Fukushima T, Aida T. Ionic liquids for soft functional materials with carbon nanotubes. Chemistry. 2007;13:5048-58.

40. Paul TC, Morshed AKMM, Fox EB, Khan JA. Thermal performance of $\mathrm{Al}_{2} \mathrm{O}_{3}$ nanoparticle enhanced ionic liquids (NEILs) for concentrated solar power (CSP) applications. Int J Heat Mass Transf. 2015;85:585-94.

41. Sharma S, Gupta SM. Preparation and evaluation of stable nanofluids for heat transfer application: a review. Exp Therm Fluid Sci. 2016;79:202-12.

42. Gupta AK, Wells S. Surface-modified superparamagnetic nanoparticles for drug delivery: preparation, characterization, and cytotoxicity studies. IEEE Trans Nanobiosci. 2004;3:66-73.

43. Sharma SK, Gupta SM. Preparation and evaluation of stable nanofluids for heat transfer application: a review. Exp Therm Fluid Sci. 2016;79:202-12.

44. Mukherjee S, Paria S. Preparation and stability of nanofluids-a review. IOSR J Mech Civ Eng. 2013;9:63-9.

45. Chou J-C, Liao LP. Study on $\mathrm{pH}$ at the point of zero charge of $\mathrm{TiO}_{2} \mathrm{pH}$ ion-sensitive field effect transistor made by the sputtering method. Thin Solid Films. 2005;476:157-61.

46. Wen D, Ding Y. Experimental investigation into the pool boiling heat transfer of aqueous based $\gamma$-alumina nanofluids. J Nanopart Res. 2005;7:265-74.

47. Wang W, Zhang Y, Li B, Han H, Gao X. Influence of geometrical parameters on turbulent flow and heat transfer characteristics in outward helically corrugated tubes. Energy Convers Manag. 2017;136:294-306.

48. Wang W, Zhang Y, Li B, Li Y. Numerical investigation of tubeside fully developed turbulent flow and heat transfer in outward corrugated tubes. Int J Heat Mass Transf. 2018;116:115-26.

49. S. Rashidi, M. Eskandarian, O. Mahian, S. Poncet, Combination of nanofluid and inserts for heat transfer enhancement. J Therm Anal Calorm. 2018;1-24.

50. Aybar HŞ, Sharifpur M, Azizian MR, Mehrabi M, Meyer JP. A review of thermal conductivity models for nanofluids. Heat Transf Eng. 2015;36:1085-110.

51. Gupta M, Singh V, Kumar R, Said Z. A review on thermophysical properties of nanofluids and heat transfer applications. Renew Sustain Energy Rev. 2017;74:638-70.

52. Yang L, Xu J, Du K, Zhang X. Recent developments on viscosity and thermal conductivity of nanofluids. Powder Technol. 2017;317:348-69.

53. Murshed SMS, Estellé P. A state of the art review on viscosity of nanofluids. Renew Sustain Energy Rev. 2017;76:1134-52.

54. Bashirnezhad K, Rashidi MM, Yang Z, Bazri S, Yan W-M. A comprehensive review of last experimental studies on thermal conductivity of nanofluids. $\mathrm{J}$ Therm Anal Calorim. 2015;122:863-84.

55. Kakaç S, Pramuanjaroenkij A. Single-phase and two-phase treatments of convective heat transfer enhancement with nanofluids-a state-of-the-art review. Int $\mathrm{J}$ Therm Sci. 2016;100:75-97.

56. Maxwell JC. A treatise on electricity and magnetism. Oxford: Clarendon Press; 1881.

57. Hamilton RL, Crosser O. Thermal conductivity of heterogeneous two-component systems. Ind Eng Chem Fundam. 1962;1:187-91.

58. Garnett JM. VII. Colours in metal glasses, in metallic films, and in metallic solutions.-II. Philos Trans R Soc Lond A. 1906;205:237-88.

59. Bruggeman VD. Berechnung verschiedener physikalischer Konstanten von heterogenen Substanzen. I. Dielektrizitätskonstanten und Leitfähigkeiten der Mischkörper aus isotropen Substanzen. Ann Phys. 1935;416:636-64.

60. Xuan Y, Li Q, Hu W. Aggregation structure and thermal conductivity of nanofluids. AIChE J. 2003;49:1038-43. 
61. Yu W, Choi S. The role of interfacial layers in the enhanced thermal conductivity of nanofluids: a renovated Maxwell model. J Nanopart Res. 2003;5:167-71.

62. Yamada E, Ota T. Effective thermal conductivity of dispersed materials (Effektive Wärmeleitfähigkeit in dispersen Systemen). Wärme-und Stoffübertragung. 1980;13:27-37.

63. Yang L, Xu X, Jiang W, Du K. A new thermal conductivity model for nanorod-based nanofluids. Appl Therm Eng. 2017;114:287-99.

64. Pak BC, Cho YI. Hydrodynamic and heat transfer study of dispersed fluids with submicron metallic oxide particles. Exp Heat Transf Int J. 1998;11:151-70.

65. Xuan Y, Roetzel W. Conceptions for heat transfer correlation of nanofluids. Int J Heat Mass Transf. 2000;43:3701-7.

66. O’Hanley H, Buongiorno J, McKrell T, Hu L-W. Measurement and model validation of nanofluid specific heat capacity with differential scanning calorimetry. Adv Mech Eng. 2012;4:181079.

67. Murshed SS. Simultaneous measurement of thermal conductivity, thermal diffusivity, and specific heat of nanofluids. Heat Transf Eng. 2012;33:722-31.

68. Vajjha RS, Das DK. Specific heat measurement of three nanofluids and development of new correlations. J Heat Transf. 2009;131:071601.

69. Pakdaman MF, Akhavan-Behabadi M, Razi P. An experimental investigation on thermo-physical properties and overall performance of MWCNT/heat transfer oil nanofluid flow inside vertical helically coiled tubes. Exp Therm Fluid Sci. 2012;40:103-11.

70. Sekhar YR, Sharma K. Study of viscosity and specific heat capacity characteristics of water-based $\mathrm{Al}_{2} \mathrm{O}_{3}$ nanofluids at low particle concentrations. J Exp Nanosci. 2015;10:86-102.

71. Einstein A. A new determination of molecular dimensions. Ann Phys. 1906;19:289-306.

72. Shun-song G, Zhong-yang L, Tao W, Jia-fei Z, Ke-fa C. Viscosity of monodisperse silica nanofluids. Bull Chin Ceram Soc. 2006;5:012.

73. Graham AL. On the viscosity of suspensions of solid spheres. Appl Sci Res. 1981;37:275-86.

74. Krieger IM, Dougherty TJ. A mechanism for non-Newtonian flow in suspensions of rigid spheres. Trans Soc Rheol. 1959;3:137-52.

75. Chen H, Ding Y, Tan C. Rheological behaviour of nanofluids. New J Phys. 2007;9:367.

76. Selvakumar RD, Dhinakaran S. Effective viscosity of nanofluids-a modified Krieger-Dougherty model based on particle size distribution (PSD) analysis. J Mol Liq. 2017;225:20-7.

77. White FM, Corfield I. Viscous fluid flow. New York: McGrawHill; 2006.

78. Andreu-Cabedo P, Mondragon R, Hernandez L, MartinezCuenca R, Cabedo L, Julia JE. Increment of specific heat capacity of solar salt with $\mathrm{SiO}_{2}$ nanoparticles. Nanoscale Res Lett. 2014;9:582.

79. Chieruzzi M, Cerritelli GF, Miliozzi A, Kenny JM, Torre L. Heat capacity of nanofluids for solar energy storage produced by dispersing oxide nanoparticles in nitrate salt mixture directly at high temperature. Sol Energy Mater Sol Cells. 2017;167:60-9.

80. Chieruzzi M, Cerritelli GF, Miliozzi A, Kenny JM. Effect of nanoparticles on heat capacity of nanofluids based on molten salts as PCM for thermal energy storage. Nanoscale Res Lett. 2013;8:448.

81. Tiznobaik H, Shin D. Enhanced specific heat capacity of hightemperature molten salt-based nanofluids. Int J Heat Mass Transf. 2013;57:542-8.
82. Shin D, Banerjee D. Enhanced specific heat of silica nanofluid. J Heat Transf. 2011;133:024501.

83. Tiznobaik H, Banerjee D, Shin D. Effect of formation of "long range" secondary dendritic nanostructures in molten salt nanofluids on the values of specific heat capacity. Int $\mathbf{J}$ Heat Mass Transf. 2015;91:342-6.

84. Jo B, Banerjee D. Enhanced specific heat capacity of molten salt-based nanomaterials: effects of nanoparticle dispersion and solvent material. Acta Mater. 2014;75:80-91.

85. Ho MX, Pan C. Optimal concentration of alumina nanoparticles in molten Hitec salt to maximize its specific heat capacity. Int $\mathbf{J}$ Heat Mass Transf. 2014;70:174-84.

86. Shin D, Banerjee D. Enhanced thermal properties of $\mathrm{SiO}_{2}$ nanocomposite for solar thermal energy storage applications. Int J Heat Mass Transf. 2015;84:898-902.

87. Ueki Y, Fujita N, Kawai M, Shibahara M. Thermal conductivity of molten salt-based nanofluid. AIP Adv. 2017;7:055117.

88. Lasfargues M, Cao H, Geng Q, Ding Y. Rheological analysis of binary eutectic mixture of sodium and potassium nitrate and the effect of low concentration $\mathrm{CuO}$ nanoparticle addition to its viscosity. Materials. 2015;8:5194-204.

89. Jung S. Numerical and experimental investigation of inorganic nanomaterials for thermal energy storage (TES) and concentrated solar power (CSP) applications. College Station: Texas A \& M University; 2012.

90. Jo B, Banerjee D. Viscosity measurements of multi-walled carbon nanotubes-based high temperature nanofluids. Mater Lett. 2014;122:212-5.

91. Ho MX, Pan C. Experimental investigation of heat transfer performance of molten HITEC salt flow with alumina nanoparticles. Int J Heat Mass Transf. 2017;107:1094-103.

92. Bellos E, Tzivanidis C, Tsimpoukis D. Thermal, hydraulic and exergetic evaluation of a parabolic trough collector operating with thermal oil and molten salt based nanofluids. Energy Convers Manag. 2018;156:388-402.

93. Nieto de Castro CA, Lourenco MJV, Ribeiro APC, Langa E, Vieira SIC. Thermal properties of ionic liquids and ionanofluids of imidazolium and pyrrolidinium liquids. J Chem Eng Data. 2010;55:653-61.

94. Paul TC, Morshed A, Fox EB, Khan JA. Enhanced thermophysical properties of NEILs as heat transfer fluids for solar thermal applications. Appl Therm Eng. 2017;110:1-9.

95. Fox EB, Visser AE, Bridges NJ, Amoroso JW. Thermophysical properties of nanoparticle-enhanced ionic liquids (NEILs) heattransfer fluids. Energy Fuels. 2013;27:3385-93.

96. Chen W, Zou C, Li X. An investigation into the thermophysical and optical properties of SiC/ionic liquid nanofluid for direct absorption solar collector. Sol Energy Mater Sol Cells. 2017;163:157-63.

97. França JM, de Castro CAN, Pádua AA. Molecular interactions and thermal transport in ionic liquids with carbon nanomaterials. Phys Chem Chem Phys. 2017;19:17075-87.

98. Wang B, Wang X, Lou W, Hao J. Ionic liquid-based stable nanofluids containing gold nanoparticles. J Colloid Interface Sci. 2011;362:5-14.

99. Bridges NJ, Visser AE, Fox EB. Potential of nanoparticle-enhanced ionic liquids (NEILs) as advanced heat-transfer fluids. Energy Fuels. 2011;25:4862-4.

100. Minea A-A, El-Maghlany WM. Natural convection heat transfer utilizing ionic nanofluids with temperature-dependent thermophysical properties. Chem Eng Sci. 2017;174:13-24. 